\title{
THE FINE STRUCTURE OF THE
}

\section{COMPARATIVE}

\author{
Pavel Caha \\ Karen De Clercq \\ Guido Vanden Wyngaerd*
}

\begin{abstract}
The paper provides evidence for a more articulated structure of the comparative as compared with the one in Bobaljik (2012). We propose to split up Bobaljik's CMPR head into two distinct heads, C1 and C2. Looking at Czech, Old Church Slavonic and English, we show that this proposal explains a range of facts about suppletion and allomorphy. A crucial ingredient of our analysis is the claim that ad-

\footnotetext{
* The authors are listed in alphabetical order. We wish to thank the anonymous reviewers for Studia Linguistica, Anna Szabolcsi, Edwin Williams, the ComForT research group at KU Leuven, as well as the audience at the 2018 Olinco conference in Olomouc for their feedback. Pavel Caha's work on this paper was supported by a grant from the Czech Science Foundation (GAČR) number GA17-10144S.
} 
jectival roots are not a-categorial, but spell out adjectival functional structure. Specifically, we argue that adjectival roots come in various types, differing in the amount of functional structure they spell out. In order to correctly model the competition between roots, we further introduce a Faithfulness Restriction on Cyclic Override, which allows us to dispense with the Elsewhere Principle.

\section{Introduction}

The seminal study of Bobaljik (2012) has put the morphosyntax of degree comparison firmly on the research agenda. Central to his claims is the Containment Hypothesis (Bobaljik 2012:4):

(1) Containment Hypothesis

The representation of the superlative properly contains that of the comparative.

A language like Czech provides overt morphological evidence for this hypothesis, in that the marker of the comparative (-ějš) also shows up in the superlative, which adds the prefix $n e j-$ to the comparative form: ${ }^{1}$

1 The final vowels in these forms are concord markers. We ignore them in what follows. 
(2)

\begin{tabular}{llll} 
POS & CMPR & SPRL & \\
\hline mil-ý & mil-ejš-í & nej-mil-ejš-í & 'nice/kind' \\
červen-ý & červen-ějš-í & nej-červen-ějš-í & 'red' \\
hloup-ý & hloup-ějš-í & nej-hloup-ějš-í & 'stupid' \\
bujar-ý & bujař-ejš-í & nej-bujař-ejš-í & 'merry'
\end{tabular}

The syntax Bobaljik proposes is accordingly as in (3). The crucial part of the tree is the containment relation between the degrees, such that the superlative contains the comparative, which in turn contains the positive adjective (A). The direction of branching (and the corresponding order of the heads) is subject to cross-linguistic variation, adjusted below to fit the Czech pattern of nej-hloup-ějšs- $i$ 'most stupid':

(3)

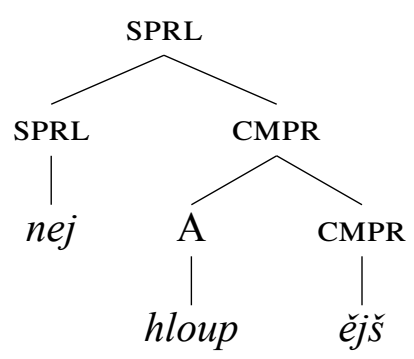

In this paper, we want to take this proposal a step further and propose (following in part Bopp 1833, as well as Caha 2017a;b and De Clercq \& Vanden Wyngaerd 2017) that the CMPR head in the above tree needs to be split up into two distinct heads, as shown in (4), with - ěj spelling out $\mathrm{C} 1$ and $-\check{s}$ spelling out $\mathrm{C} 2$ : 
(4)

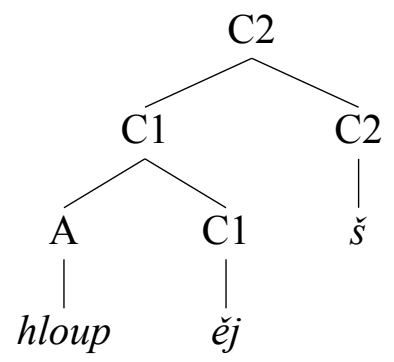

In section 2, we present evidence for this structure coming from the allomorphy of the comparative markers in Czech. In section 3, we present the details of our theoretical framework (Nanosyntax). In sections 4 and 5, we extend the analysis developed on the basis of the Czech to data from Old Church Slavonic and English. In section 6, we turn to suppletion in Czech and English, and show how the bi-partite structure explains an interaction between the allomorphs of the comparative and root suppletion. In section 7, we argue that the Elsewhere Principle should be abandoned, and its effects captured by the Faithfulness Restriction on spellout.

\section{Allomorphy of the Czech comparative}

\subsection{The three allomorphs}

As we have shown in (2) above, the Czech comparative can be formed by suffixing -ějš to the root. We give a couple more examples below. 


\begin{tabular}{lllll} 
POS & CMPR & \multicolumn{2}{c}{ palatalisation } & gloss \\
\hline stroh-ý & strož-ejš-í & {$[\mathrm{h} \rightarrow 3]$} & (velar) & 'austere' \\
divok-ý & divoč-ejš-í & {$[\mathrm{k} \rightarrow \widehat{\mathrm{t} f}]$} & $($ velar) & 'wild' \\
kulat-ý & kulat-ějš-í & {$[\mathrm{t} \rightarrow \mathrm{c}]$} & (alveolar) & 'round' \\
bujar-ý & bujař-ejš-í & {$[\mathrm{r} \rightarrow \mathrm{r}]$} & (alveolar) & 'merry' \\
benign-í & benign-ějš-í & {$[\mathrm{n} \rightarrow \mathrm{n}]$} & (alveolar) & 'benign' \\
hloup-ý & hloup-ějš-í & {$[\mathrm{p} \rightarrow \mathrm{pj}]$} & (labial) & 'stupid' \\
blb-ý & blb-ějš-í & {$[\mathrm{b} \rightarrow \mathrm{bj}]$} & (labial) & 'stupid'
\end{tabular}

The suffix $-\check{e} j \check{s}$ is the only productive comparative marker and newly coined gradable adjectives follow this pattern (see 'benign' for an example).

To get a full picture, it is important to take note of the consonant mutations (in effect, palatalisations) that affect the base to which -ějš attaches. Palatalisation affects the final consonant in a way that is shown in the last column of the table. The palatalisations in (5) are not an automatic response of the base to the following phoneme $[\varepsilon]$, as there are $[\varepsilon]$-initial suffixes which do not trigger palatalisation. Hence, it is an arbitrary property of the vowel/suffix that it triggers palatalisation, and so this needs to be somehow encoded in the lexicon. The traditional spelling of the -ějš suffix reflects this by placing a diacritic over the vowel: $\check{e}$ is an $e$ which triggers the palatalisation of the preceding con- 
sonant. As we shall see below, there are different types of palatalisation triggers in Czech, with different properties. For the purposes of the discussion below, we will note the palatalisation trigger in the -ějš suffix as $\operatorname{PAL}_{\mathrm{VAL}}$, i.e. $\check{e} j \check{s}=\mathrm{PAL}_{\mathrm{VAL}} e j \check{s}$; the subscript indicates that palatalisation affects velars, alveolars, and labials. Such a notation serves the purpose that it transforms the non-segmental marker into a segmental-like object that we can work with in the morphological analysis. At the same time, PAL is admittedly nothing more than a stand-in for an actual phonological analysis of how palatalisation works, which we deliberately leave aside. In the orthography, when -ějš is attached to the base, palatalisations are sometimes marked on the preceding consonant (as in $\check{z} e, \check{c} e$,

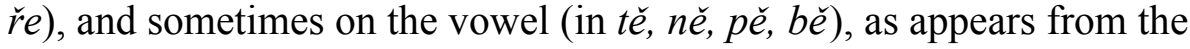
table (5).

The next point in our description is the allomorphy of the comparative marker. Specifically, as the traditional descriptions recognise (Dokulil et al. 1986; Karlík et al. 1995; Osolsobě 2016), there are two more ways of forming comparatives. The first of these is to attach only $-\check{s}$, as in the forms below: 
(6)

\begin{tabular}{lllll} 
POS & CMPR & \multicolumn{2}{c}{ palatalisation } & gloss \\
\hline drah-ý & draž-š-í & {$[\mathrm{h} \rightarrow 3]$} & (velar) & 'expensive' \\
tich-ý & tiš-š-í & {$\left[\mathrm{x} \rightarrow \int\right]$} & (velar) & 'silent' \\
bohat-ý & bohat-š-í & - & (alveolar) & 'rich' \\
star-ý & star-š-í & - & (alveolar) & 'old' \\
slab-ý & slab-š-í & - & (labial) & 'weak'
\end{tabular}

It can be observed that $-\check{S}$ also triggers palatalisations, but this process affects only velars, while alveolars and labials are unaffected. This suggests that if palatalisation is to be seen as an effect of juxtaposing the base and the comparative $-\check{s}$, then $-\check{s}($ like $-\check{e} j \check{s})$ must be accompanied by a PAL diacritic too. Importantly, since the palatalisations triggered by $-\check{S}$ are of a different kind than those associated to $-\check{e} j \check{s}$, we will introduce a different palatalisation trigger for this case, namely $\operatorname{PAL}_{\mathrm{V}}$ (for the palataliser of velars). As we shall show below, there is also a third type of palataliser in Czech, $\mathrm{PAL}_{\mathrm{VA}}$, which is found with the soft declension marker $-i$, and which palatalises velars and alveolars but not labials. This situation is summarised in (7).

(7) a. PAL $\mathrm{VAL}_{\mathrm{VAL}}$ palatalises preceding velars, alveolars, and labials (e.g. $-\check{e} j)$

2 Orthography requires that tišši 'more silent' is written with double $\check{s}$, but it is pronounced with a single $\check{s}$ due to degemination. 
b. PAL $_{\mathrm{VA}}$ palatalises preceding velars and alveolars (e.g. $-i$ )

c. PAL palatalises preceding velars (e.g. $-\check{S},-\check{s} t)$

This has also consequences for the morphological analysis of the palatalisations: given that the palatalisations are different for different allomorphs, we will not segment out 'palatalisation' as something that marks all comparatives, since there is no unique palatalisation. Rather, the two types of palatalisation that we see in the comparative suffixes are each firmly connected to the particular allomorph that gets attached to the base.

Note finally that a purely phonological account of the distribution of the allomorphs $-\check{e} j \check{s}$ and $-\check{s}$ seems unlikely. For example, the adjectival root kulat- 'round' from (6) is similar to bohat- 'rich' in (7), but they pattern differently. Similarly, star- 'old' in (7) ends in the same segments as bujar - 'merry' in (6), and yet they differ in allomorph selection. For this reason, we will treat $-\check{s}$ here as a morphologically conditioned allomorph of -ějš.

The third (and final) allomorph recognised in the traditional descriptions is a zero marker. Some examples are given in (8). 
(8)

\begin{tabular}{|c|c|c|c|}
\hline POS & CMPR & $\begin{array}{l}\text { palatalisation } \\
{[\mathrm{k} \rightarrow \widehat{\mathrm{t} f}]}\end{array}$ & gloss \\
\hline kluz-k-ý & kluz-k-ø-í & kluz-č-ø-í & 'slippery' \\
\hline leh-k-ý & leh-k-ø-í & leh-č-ø-í & 'light/easy' \\
\hline hez-k-ý & hez-k-ø-í & hez-č-ø-1́ & 'pretty' \\
\hline měk-k-ý & měk-k-ø-í & měk-č-ø-í & 'soft' \\
\hline ten-k-ý & ten-k-ø-í & ten-čc-ø-1́ & 'thin' \\
\hline vlh-k-ý & vlh-k-ø-í & vlh-č-ø-í & 'wet' \\
\hline
\end{tabular}

In these representations, which represent the traditional analysis of these forms, the comparative marker is taken to be zero (indicated by the $\varnothing$ sign). The adjectives in question all have a final $-k$, a derivational suffix, which we will come back to in Section 2.4 below. In the comparative, $-k$ is is followed by the soft agreement marker $-i$. The soft agreement marker is independently known to trigger palatalisation of velars $([\mathrm{k} \rightarrow$ โf]; see (7b) above). As a result, in the comparative $-k$ appears as $-\check{c}$.

The existence of a third, zero, allomorph (while not crucial) does have a role to play in our analysis, and so we need to consider a potential alternative to the traditional analysis. The alternative would be to reduce the pattern in (8) to suffixation by $-\check{s}$, i.e. the second allomorph (illustrated in (6) above). This alternative analysis is represented in (9). 
(9)

\begin{tabular}{|c|c|c|c|}
\hline POS & CMPR & $\begin{array}{l}\text { palatalisation } \\
{\left[\mathrm{k} \rightarrow \widehat{\mathrm{t} \int}\right]}\end{array}$ & $\begin{array}{l}\text { degemination } \\
{\left[\widehat{\left[\mathrm{t} \int\right.} \rightarrow \widetilde{\mathrm{t} f}\right]}\end{array}$ \\
\hline kluz-k-ý & kluz-k-š-í & kluz-č-š-í & kluz-č-í \\
\hline leh-k-ý & leh-k-š-í & leh-čc-š-í & leh-č-í \\
\hline hez-k-ý & hez-k-š-í & hez-č-š-í & hez-č-í \\
\hline měk-k-ý & měk-k-š-í & měk-č-š-í & měk-č-í \\
\hline ten-k-ý & ten-k-š-í & ten-č-šs-í & ten-č-í \\
\hline vlh-k-ý & vlh-k-š-í & vlh-č-šs-í & vlh-č-í \\
\hline
\end{tabular}

The idea is that the sequence $k-\check{s}$ (in the second column) is subjected to phonological processes, ultimately producing the same result as the analysis where $-i$ is attached directly to the adjective. Specifically, $-\check{S}$ would first trigger the palatalisation of $k$ as shown in the third column of (9). After that, the [ $\left[\widehat{\mathrm{t}} \int\right]$ cluster is simplified to [ $[\mathrm{t}]$ by degemination (see also footnote 2), yielding the surface forms as in the final column of (9). These are identical to the forms in (8), i.e. the two analyses yield the same output.

The phonological derivation in (9) is not purely hypothetical. Its existence is supported by a parallel derivation found in the case of locative adjectives. In the NOM.PL, these adjectives have the suffix $-\check{s} t-i$. This suffix triggers no change in alveolar-final stems, as shown in the 'Norwegian' column of (10). This fact shows that the $-\check{s} t$ suffix be- 
longs to the same class as the comparative suffix $-\check{s}$, in that it does not trigger palatalisation of alveolars. Like all palatalisation triggers, $-\check{s} t$ triggers the palatalisation of velars $([\mathrm{h} \rightarrow 3, \mathrm{k} \rightarrow \widehat{\mathrm{t}}]])$, as shown in the two rightmost columns of (10). When $-\check{s} t$ follows a $-k$-final base, as in the 'Turk(ish)' column, palatalisation ([k $\rightarrow \widetilde{\mathrm{t}}]$ ) is followed by degemination $\left(\left[\widehat{\mathrm{t} f} \int \rightarrow \widehat{\mathrm{t} f}\right]\right)$, yielding the $[\widehat{\mathrm{t} f}]$ output from the underlying $k-\check{s}$.

\begin{tabular}{|c|c|c|c|}
\hline & 'Norwegian' & 'Prague' & 'Turk(ish)' \\
\hline NOUN & nor & Prah-a & turek \\
\hline ADJECTIVE & nor-št-í & prah-št-í & turek-št-í \\
\hline palatalisation & - & praž-št-í & tureč-št-1́ \\
\hline degemination & - & - & tureč-t-í \\
\hline output & no[r $\left.\int\right] t^{\prime}$ & $\operatorname{pra}\left[3 \int\right] \mathrm{tí}$ & $\operatorname{ture}[\widehat{\mathrm{t} f}] \mathrm{tí}^{\prime}$ \\
\hline
\end{tabular}

The sequence of phonological processes we see at work in the final column of (10) is the same as the one that are postulated in the alternative analysis of the (superficially) zero-marked comparatives in (9).

Summing up, we see that zero marking of the comparative and $-\check{S}$ affixation yield the same surface forms for $-k$ final stems. The issue of the proper analysis of the comparative is therefore hard to decide (see Scheer 2001:34, who also remains agnostic about which option should be chosen). 
However, there are dialects with additional zero-marked forms, and these allow us to tease these analyses apart, supporting the zero-marking account. In order to understand the facts, let us first show what happens to a base to which the soft adjectival $-i$ attaches. For instance, relational 'kind-possessive' adjectives are often derived from the underlying nouns by simply placing the soft declension marker $-i$ after the root of the noun, as in (11).

\begin{tabular}{llcll} 
NOUN & ADJECTIVE & \multicolumn{2}{c}{ palatalisation } & gloss \\
\hline vlk & vlč-í & {$[\mathrm{k} \rightarrow \widehat{\mathrm{t} f}]$} & (velar) & 'wolf' \\
vydr-a & vydř-í & {$[\mathrm{r} \rightarrow \mathrm{r}]$} & (alveolar) & 'otter' \\
$\sup$ & sup-í & - & (labial) & 'vulture'
\end{tabular}

These adjectives are most naturally used in context where English would have compounds, like 'a wolf track' or 'a vulture nest.' In these contexts, they seem semantically not very different from nouns, which gives us some grounds to believe that we are actually looking at examples where a nominal root is directly followed by a soft agreement marker. Certainly, there is no suspicion here that the comparative $-\check{S}$ may be involved. What is relevant for us are the palatalisations we observe in these examples. As the last column of the table (11) brings out, these are of the type $\mathrm{PAL}_{\mathrm{VA}}$ : velars and alveolars are palatalised, while labials remain unaffected. 
With this background in mind, let us now turn to the dialectal comparative forms, which (as we propose) feature a zero comparative marker. They come from the dialect of North-East Bohemia (Bachmannová 2007), and they are given in the table below, along with the standard forms. The difference between the two sets of forms is not a matter of a difference in the application of phonological processes, but a consequence of the roots belonging to different morphological classes. The standard form takes the - $\check{e} j s ̌$ allomorph, the dialectal forms take a different one.

\begin{tabular}{lllll} 
& St. Czech & N-E Bohemia & palatalisation & gloss \\
POS & CMPR & CMPR & & \\
\hline ostr-ý & ostřr-ejš-í & ostřr-ø-í & {$[\mathrm{r} \rightarrow \mathrm{r}]$} & 'sharp' \\
mokr-ý & mokřr-ejš-í & mokř- $\varnothing-1$ & {$[\mathrm{r} \rightarrow \underset{r}{\mathrm{r}}]$} & 'wet'
\end{tabular}

These examples are unproblematic for the idea that there is no overt comparative marker. As we saw in (11), the soft-declension marker $-i$ belongs to the $\mathrm{PAL}_{\mathrm{VA}}$ class, i.e. it triggers the palatalisation of both velars and alveolars, which is what we observe in (12).

On the other hand, the $-\check{S}$ based analysis of zero marking cannot be applied to the dialectal forms. This is because the comparative suffix $-\check{S}$ belongs to the $\mathrm{PAL}_{\mathrm{V}}$ class, which does not trigger the palatalisation of alveolars, as shown in (6) above. A minimal contrast can be observed between a form like $\operatorname{star}-\check{s}-\bar{l}$ ' older' (no palatalisation or $r$ when followed 
by $-\check{S}$ ), and the forms in (12), where $r$ is palatalised. PAL is also attested with the $-\check{s} t$ suffix, discussed in (10) above. This suffix likewise does not trigger palatalisation of $r$, i.e. we get [rf] in the output, as shown in (13).

\begin{tabular}{cccl} 
NOUN & ADJECTIVE & palatalisation & gloss \\
\hline bratr & bratr-št-í & - & 'brother'
\end{tabular}

If the underlying sequence of (12) were ostr-š- $i$, we would expect $o s t r-\check{s}-\dot{i}$, with non-palatalised $r$, to surface here. The dialectal forms thus seem best captured as a case where the zero suffix has a wider distribution as compared to the standard language, and we shall therefore assume that the traditional descriptions are correct in proposing the existence of a zero allomorph for the Standard Czech $k$-adjectives as well. At the same time, we also wish to point out here that the analysis of the $k$ adjectives that we develop only needs a minor modification if they are taken to instantiate the second allomorph $(-\bar{s})$.

Summing up the traditional descriptions, the two non-productive allomorphs of the productive comparative marker -ějjšs $i$ correspond to various degrees of its reduction, going from left to right, as (14) brings out:

$$
\text { a. } \quad \check{e} j \check{s}-i
$$



b. $\quad \check{s}-\grave{l}$
c. $-i$

One of the main goals of this paper is to present a theory that explains how such a reduction works and that makes some non-trivial predictions about how this type of reduction interacts with root suppletion.

\subsection{Decomposing the comparative}

Moving now to the actual account, it is trivial to provide an analysis for the difference between the $-\varnothing$ class and the $-\check{S}$ class. This difference is perfectly analogous to pairs such as sheep—sheep-ø vs. heap-heap-s: one (minor) class has a null marker where the other class has an overt marker. This simple logic can be extended to the difference between $-\check{S}$ $i$ and $-\check{e} j \check{s}-i$, provided we assume that the suffix -ějš actually splits into $-\check{e} j$ and $-\check{s}$. If that is so, the $-\check{e} j \check{s}$ class becomes an $-\check{e} j-\check{s}$ class, and the $-\check{s}$ class then becomes a $-\varnothing-\check{s}$ class, with the morpheme $-\check{S}$ shared by both forms. In structural terms, this means that comparatives have two heads, $\mathrm{C} 1$ and $\mathrm{C} 2$, where the $-\check{e} j$ exponent spells out $\mathrm{C} 1$, and $-\check{S}$ spells out $\mathrm{C} 2$, in the manner indicated in (15). For comparatives which lack the $-\check{e} j$ exponent, we assume, for now, that there is simply a zero allomorph of $-\check{e} j$, as indicated in the tree in $(16) .^{3}$

\footnotetext{
3 As before, the structures are adjusted to fit the surface order of Czech, which is the mirror image ordering of the underlying functional sequence (see Cinque 2005). As
} 
The -ějš comparative

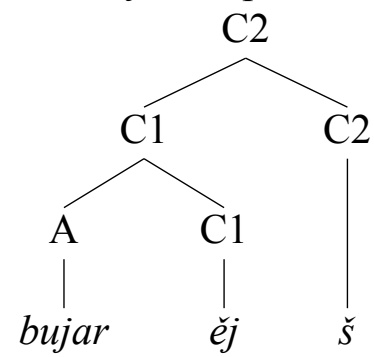

(16) The $-\check{s}$ comparative

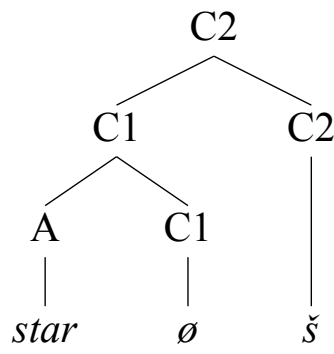

If only one position of exponence were assumed, we would need to store both $-\check{e} j \check{s}$ and $-\check{s}$ as separate allomorphs (in competition for a single position), and their partial identity would be purely accidental.

The third class of comparatives can still be captured as a reduced version of (16), with both markers silent, as shown in (17).<smiles>COC(=O)C(Cl)Cl</smiles>

Decomposing the comparative -ějš into two morphemes $-\check{e} j$ and $-\check{s}$ thus allows for a 'principled' approach to the gradual reduction of the full marker, an account which cannot be stated without such a decomposi-

in Cinque's work, we analyse mirror orders as arising through a series of standard movement operations, which affect phrasal nodes and move them either cyclically (i.e. spec-to-spec), or roll-up style. We highlight the mechanics of these movements in the next section. 
tion. By 'principled approach' we mean an approach where the similarity between $-\check{e} j-\check{s}$ and $-\check{s}$ is not accidental: they share an identical morpheme.

Interestingly, it turns out that there is independent evidence that - ěj $\breve{s}$ should be split into two parts indeed. The evidence comes from comparative adverbs, seen in the second column of (18). Here the $-\check{s}$ part of the comparative adjective is systematically missing.

\begin{tabular}{lcc} 
CMPR ADJ & CMPR ADV & \\
\hline bujař-ej-š-í & bujař-ej- i & 'merrier' \\
rychl-ej-š-í & rychl-ej- i & 'faster' \\
červen-ěj-š-í & červen-ěj- i & 'redder' \\
hloup-ěj-š-í & hloup-ěj- i & 'sillier' \\
bujař-ej-š-í & bujař-ej- i & 'merrier'
\end{tabular}

The absence of $-\check{S}$ in the adverbs (highlighted by a gap between $\check{e} j$ and the adverbial marker) is hard to attribute to phonology, because the adverbial markers are vowels like the agreement marker $-i$, and they differ only in length. But if $-\check{S}$ is not deleted due to a contact with the following vowel, it must correspond to a separate morpheme that is simply missing in all the adverbs, a conclusion which independently supports the split analysis. We will come back briefly to the adverbial forms in section 4 . 


\subsection{Root types and the distribution of zeroes}

With the 'split-CMPR' proposal in place, we turn to an interesting asymmetry in the way zero morphology is distributed in Czech comparative adjectives depending on the stem chosen. The stem may be morphologically simplex, corresponding to the root only, or it may be complex, as with $-k$ derived adjectives. In this section, we are interested in how roots control zero morphology in the positions corresponding to $\mathrm{C} 1$ and $\mathrm{C} 2$, and we turn to stems in the next section.

The pattern we shall explore is that we find roots that require a zero marker next to them, with the outer marker overt, as in (19b) (overt exponence is represented by $\alpha$ ). Furthermore, if the analysis in (17) is on the right track, the outer morpheme can also be silent, but only if the inner one is, so that zero morphology spreads from the root outwards, as in $(19 \mathrm{c})$. What we do not find is a case where a particular root requires a pattern in which the inner marker is overt and the outer zero, as in (19d).
C1 C2
a. ATTESTED: $\sqrt{\text { Type } 1}-\alpha \quad-\alpha \quad$ (hloup-ěj-šsi $)$
b. ATtEsted: $\sqrt{\text { Type } 2} \quad-\varnothing \quad-\alpha \quad($ star- - - $\check{-}-i)$
c. ATtested: $\sqrt{\text { Type } 3} \quad-\varnothing \quad-\varnothing \quad($ ost $\check{r}-\varnothing-\varnothing-i)$
d. NOt ATtested: $\sqrt{\text { Type }^{*}}-\alpha \quad-\varnothing$

This pattern leads to the following generalisation: 
(20) Root-determined zeroes spread from the inside out, and cannot skip intervening heads.

Before we go on to discuss the explanation for (20), we must address some empirical issues (relevant for the generalisation), which have to do with the proper treatment of palatalisations. So far, we have analysed them as an indivisible (even if floating) part of each of the suffixes, such that in effect $\check{e} j=\operatorname{PAL}_{\mathrm{VAL}} e j$, and $\check{s}=\operatorname{PAL}_{\mathrm{V}} \check{s}$, etc. One might go a step further and argue that the PAL element is not part of the suffix to begin with.

For instance, a reviewer builds on the (diachronically motivated) idea that soft declension does not trigger palatalisation, but rather reflects the fact that the stem ends in a palatal consonant to begin with. If that is so, we have to grant the palatalisation in the third pattern an independent status, and treat it as an exponent of some comparative head. Once palatalisations are granted morphemic status, we move towards a system where we could distinguish three different components of the comparative marker instead of two, with PAL as the third element. As suggested by the reviewer, one possible segmentation of the three different patterns of comparative formation would then look as in (21), with PAL realised as $j$ after a vowel and labials (i.e., in the first pattern): 

C1 $\quad$ C2 $\quad$ C3 our analysis
a. $\sqrt{\text { Type } 1}$ PAL $_{\mathrm{VAL}} \mathrm{e}$ PAL $\check{\mathrm{s}} \quad($ hloup-ěj-šs-í)
b. $\sqrt{\text { Type } 2} \quad \varnothing \quad$ PAL $\quad \check{\mathrm{s}} \quad(\operatorname{star}-\varnothing-\check{s}-\hat{\imath})$
c. $\sqrt{\text { Type } 3} \quad \varnothing \quad$ PAL $\quad \varnothing \quad(k l u z-k-\varnothing-\varnothing-i$, ostr- $\varnothing-\varnothing-i)$

Here the palatalisation of $\sqrt{\text { Type } 3}$ would be caused, not by the soft declension marker, but by the palatal element in C2. Such analysis would then contradict our claim that the root-determined zeroes can only spread from the inside out, since $\mathrm{C} 3$ would be silent where $\mathrm{C} 2$ is realised by PAL.

While we find the alternative worth considering, one problem we see in this move is that there is no independent evidence for decomposition. Recall that our argument for splitting $-\check{e} j$ and $-\check{S}$ rests in part on the fact that $-\check{s}$ is missing in comparative adverbs, where only $-\check{e} j$ is found. Analogously, if PAL and [i:] were independent in the soft declension marker, we would want to see PAL independently of the following [i:]. But there are no forms (or parts of forms) like that; these only arise when $-i$ or other palatalisation triggers follow.

The second reason why the analysis in (21) is problematic is that the proposed decomposition works only for the standard language, because it makes the palatalisation triggers that occupy $\mathrm{C} 2$ identical. But as we have seen when looking the dialectal forms in (12), the palatalisations are actually different. In (21b), we are looking at $\mathrm{PAL}_{\mathrm{V}}$, while in (21c), 
we are dealing with $\mathrm{PAL}_{\mathrm{VA}}$. This casts doubt on the particular segmentation in (21), where an identical PAL is shared across the (b) and the (c) example.

If we wanted to make the proposal in (21) descriptively accurate, we would be rather led to structure the facts in a way as shown in (22). This proposal preserves the idea that $\mathrm{PAL}_{\mathrm{VA}}$ is an independent comparative marker (in C3 in (22)), syntactically distinct from the following agreement marker, and at the same time captures the fact that palatalisation is different in the (b) and (c) cases.

$$
\mathrm{C} 1 \quad \mathrm{C} 2 \quad \mathrm{C} 3 \quad \text { our analysis }
$$
a. $\sqrt{\text { Type } 1}$
PAL $_{\mathrm{VAL}} \mathrm{e}$
$\mathrm{PAL}_{\mathrm{V}} \breve{\mathrm{s}}$
PAL $_{\mathrm{VA}}$
(hloup-ěj-šs-í)
b. $\sqrt{\text { Type } 2}$
$\varnothing$
$\mathrm{PAL}_{\mathrm{V}} \breve{\mathrm{s}} \quad \mathrm{PAL}_{\mathrm{VA}} \quad($ star $-\varnothing-\check{S}-\bar{l})$
c. $\sqrt{\text { Type } 3}$
$\varnothing$
$\varnothing \quad$ PAL $_{\mathrm{VA}} \quad(k l u z-k-\varnothing-\varnothing-i$, ostř- $\varnothing-\varnothing-i)$

However, once we structure the facts like this, the very same generalisation concerning zero distribution emerges again: zeroes spread from the inside out. In sum, even if PAL is treated as an exponent of the comparative, the details of how palatalisations work lead us to an analysis which observes the generalisation (20). In the account that follows, we return to our original bi-componential analysis. The reason (as highlighted above) is that it is harder to defend the independence between 
$\mathrm{PAL}_{\mathrm{VA}}$ and the following agreement marker. However, if it turns out that the facts ought to be structured as in (22), this will have no theoretical consequences for the type of proposal we shall put forth. ${ }^{4}$

Let us now then turn to the explanation we propose for the asymmetrical distribution of zeroes. We argue that this follows from a theory where zero exponents arise as a consequence of non-terminal spell out, where a single lexical item may realise multiple positions in the syntactic/morphological structure (see e.g. Williams 2003; Siddiqi 2006; Starke 2009; Radkevich 2010; Haugen \& Siddiqi 2016). In such a theory, the root may spell out a unit that corresponds to multiple terminals, including one or more comparative heads. If such an approach is adopted, the original structures with zeroes (on the left) are updated as depicted on the right.

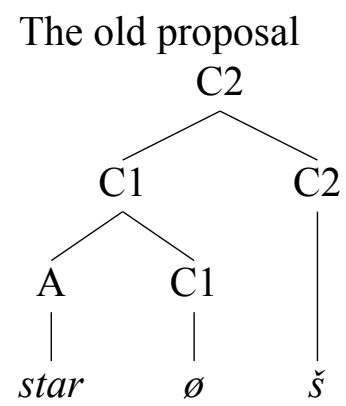

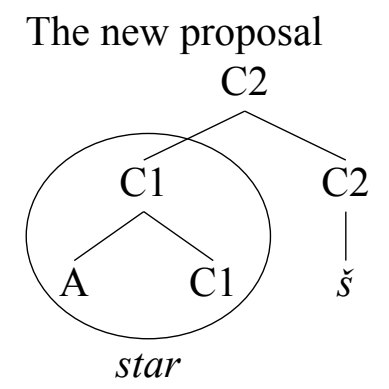

\footnotetext{
${ }^{4}$ The advantage of introducing PAL under $\mathrm{C} 3$ is that it allows for a purely phonological approach to the issue of hard/soft declension: soft declension is what one gets after soft stems, i.e. stems ending in $\mathrm{PAL}_{\mathrm{VA}}$. However, we think that the issue is more complex than this, and that there is a more substantial (morphosyntactic) difference between the two declensions. We refrain from discussing this issue in full here, as it would lead us too far afield.
} 


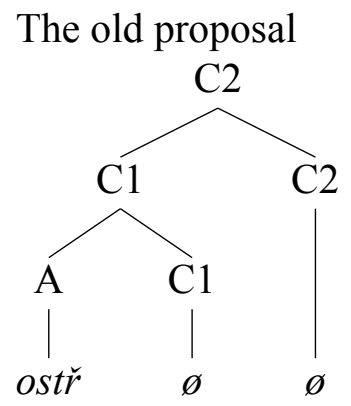

(26)

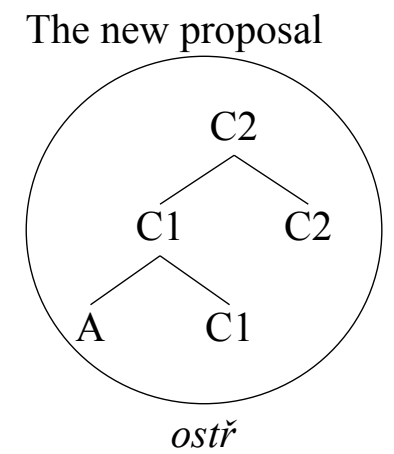

It is clear from the diagrams that if root-controlled zeroes are the product of non-terminal insertion, then they will make the two comparative markers disappear inside out, rather than in any other fashion. This derives the absence of the fourth pattern in (19), repeated (for convenience) below:
a. $\quad$ Attested: $\sqrt{\text { Type } 1} \quad-\alpha \quad-\alpha \quad$ (hloup-ěj-š-í)
b. ATTESTED: $\sqrt{\text { Type 2 }}-\varnothing \quad-\alpha \quad(\operatorname{star}-\varnothing-\check{s}-\hat{\imath})$
c. ATtESTED: $\sqrt{\text { Type } 3} \quad-\varnothing \quad-\varnothing \quad($ ostř- $\varnothing-\varnothing-i ́)$
d. NOT ATtested: $\sqrt{\text { Type }^{*}}-\alpha \quad-\varnothing$

Given the type of explanation proposed, we expect the absence of (27d) to be valid for all cases where a particular root requires a certain pattern of overt/zero exponence. However, the role of the root in triggering the pattern is crucial. Consider, for instance, the adverbs presented in (18) above, a representative instance of which is repeated in (28). 


$$
\begin{array}{lll}
\text { CMPR ADJ } & \text { CMPR ADV } \\
\hline \text { bujař-ej-š-í } & \text { bujař-ej- i 'merrier' }
\end{array}
$$

In the adverbial form of (28), the $\mathrm{C} 2$ marker $\check{s}$ is missing, while the $\mathrm{C} 1$ ěj exponent is present. This might on the face of it appear to instantiate (27d). But the crucial point is that the absence of C2 $\check{s}$ in the presence of $\mathrm{C} 1$-ěj is triggered here by 'being an adverb,' and not by 'having a particular root'. We will have more to say about the analysis of adverbs in section 4.

To sum up, we are proposing an account of the allomorphic variation in terms of a bi-partite structure, which explains why one allomorph is a reduced version of the other, and non-terminal spell out, which explains why zeroes first appear close to the root and expand outwards.

The correct pairing of the three comparative allomorphs with individual roots is accounted for by proposing different lexical entries for different classes of adjectival roots. The first class is the regular one, which merely spells out A, as shown in (29a). Adjectives that take only $-\check{S}$ in the comparative spell out a larger structure, consisting of $\mathrm{A}$ and $\mathrm{C} 1$ (see (29b)). Finally, adjectives that spell out the entire $\mathrm{A}+\mathrm{C} 1+\mathrm{C} 2$ show no CMPR marker, and their entry is as in (29c). Analysing the allomorphy this way, we dispense with diacritics that pair the right allomorph with 
the right root. The correct comparative allomorph simply corresponds to a residue that is not spelled out by a given root. ${ }^{5}$
a. Root that combines with ějš-(i) $\Leftrightarrow \quad[\mathrm{A}]$
b. Root that combines with $\check{s}-(i) \Leftrightarrow[[$ A ] C1 ]
c. Root that combines with $-(i) \Leftrightarrow[[[\mathrm{A}] \mathrm{C} 1] \mathrm{C} 2]$

The last ingredient we need to introduce in this section is the Superset Principle (we slightly modify the original formulation of Starke 2009 so as to avoid any misunderstanding).

\section{The Superset Principle:}

A lexically stored tree $\mathrm{L}$ matches a syntactic node $\mathrm{S}$ iff $\mathrm{L}$ contains the syntactic tree dominated by $\mathrm{S}$ as a subtree

The Superset Principle makes sure that these entries can also appear in the positive degree. This is particularly relevant for entries of the type in (29b) and (29c), as these are larger than the syntactic structure of the positive degree, and still they can occur in the positive degree. The Superset Principle ensures this: in the syntax, the positive degree corresponds only to the feature [A], which is contained in all the lexical entries in (29), and so any of these entries can be inserted in the positive degree. The Superset Principle also accounts for the adjectives of the

5 We will update the entries slightly in section 2.4, where we further decompose A. 
third category, which show a syncretism between the positive and the comparative degree. ${ }^{6}$

\subsection{Splitting up A}

Now recall from section 2.1 that there is a particular class of adjectives in Czech that has the suffix $-k$ in the positive and apparently a zero-marked comparative. These are repeated in the table below.

\begin{tabular}{lllll} 
POS & CMPR & gloss of A & BASE & gloss \\
\hline kluz-k-ý & kluz-č-í & 'slippery' & s-kluz & 'a slide' \\
břit-k-ý & břit-č-í & 'sharp' & břit & 'edge' (of a knife) \\
hoř-k-ý & hoř-č-í & 'bitter' & hoř-e & 'sorrow' \\
sliz-k-ý & sliz-č-í & 'slimy' & sliz & 'slime' \\
vlh-k-ý & vlh-č-í & 'wet' & vláh-a & 'dew' \\
ten-k-ý & ten-č-(í) & 'thin' & *ten & -
\end{tabular}

In the table, the stem final $-k$ is factored out as a derivational suffix, in line with traditional accounts such as Dokulil et al. (1986), Karlík et al. (1995) or Janda \& Townsend (2000:24). This segmentation is motivated by the fact that the roots to which the adjectiviser $-k$ attaches lead an

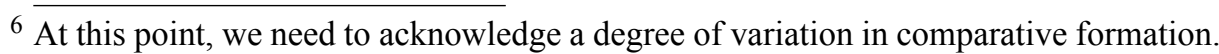
For instance, the adjective bohat $-y$ ' rich' allows for two comparative forms, namely bohat-š- $i$ (ca. 786.000 hits on Google) and bohat-ěj-š- $i$ (ca. 21.000 hits). We attribute such variation to the possibility that different speakers may assign different lexical entries to particular roots, so that some speakers store the root bohat 'rich' as C1P, others as AP (more specifically QP, cf. section 2.4), others (maybe) as both. 
independent life, as shown in the column marked BASE. Note that in some cases (e.g. 'thin'), the root is just a cranberry morpheme and does not exist independently of the adjectival context.

Such morphologically complex positives require that we split up the positive-degree A into a root feature and a functional head $\mathrm{Q}$, which we take to be a head that contributes gradability (Bresnan 1973; Corver 1997; De Clercq 2013; 2017; De Clercq \& Vanden Wyngaerd 2017). This makes enough space in the positive degree (corresponding now to a constituent dominated by Q) for both the root and the $-k$, as shown in (32). Here we assume that the (verbal) root kluz 'to slide' spells out $\sqrt{ }$, and the $-k$ suffix spells out the Q projection. ${ }^{7}$
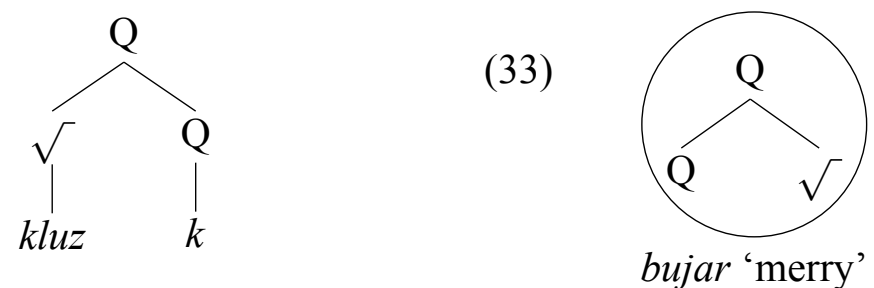

Given the semantic contribution which we have invested into the Q head (gradability), we expect that this head is present in all gradable adjectives. However, many gradable adjectives have no adjectival suffix and

\footnotetext{
${ }^{7}$ We use the notation $\sqrt{ }$ to indicate the bottom of the functional sequence for convenience only. We consider it likely that $\sqrt{ }$ in fact needs to be further decomposed into functional heads all the way down (comparable to the way $\mathrm{V}$ is decomposed into a series of functional heads in Ramchand 2008). Under this perspective, $\sqrt{ }$ should be read as a mere shorthand for a series of functional heads, the exact nature of which is yet to be determined. This issue does not affect the arguments made in this paper.
} 
their stem (the base to which the inflectional agreement is added) corresponds to the root only. We propose that such adjectives (which we discussed in the previous section) spell out the whole QP, as shown in (33).

Consequently, we must update all other types of roots (those that spell out also comparative heads) accordingly. The final lexical entries of selected roots, each belonging to one of the classes identified above, are given below.
a.
$\sqrt{ } \quad \Leftrightarrow \quad /$ kluz/
b.
$[\mathrm{QP} Q \sqrt{ }] \Leftrightarrow$ /bujar/
c.
$[\mathrm{C} 1 \mathrm{P} C 1[\mathrm{QP} \mathrm{Q} \sqrt{ }]] \Leftrightarrow / \mathrm{star} /$
d. $[\mathrm{C} 2 \mathrm{P} \mathrm{C} 2[\mathrm{C} 1 \mathrm{P} \mathrm{C} 1[\mathrm{QP} Q \sqrt{ }]]] \Leftrightarrow /$ ostř $/$

The entry (35a) is the new type of root, which we have introduced in this section: it spells out only the $\sqrt{ }$ node, and cannot spell out the whole positive degree (i.e., QP). Hence, it requires additional morphology in the positive (i.e., $-k$ ). All other root types (i.e. those in (35b-d)) spell out QP at least, and as a result, they have no suffix in the positive (save the agreement). They correspond to the three classes of roots identified in the preceding section. Bujar 'merry' type of roots (see (35b)) leave both $\mathrm{C} 1$ and $\mathrm{C} 2$ without spellout, combining with $-\check{e} j-\check{s}$ in the comparative. Star 'old' can spell out C1 in addition, combining with $-\check{S}$ in the 
comparative. Finally the dialectal ostř 'sharp' needs no additional morphology either in the positive or in the comparative. The lexical entries for the comparative suffixes are given in (35).
a. $[\mathrm{C} 1 \mathrm{P} \mathrm{C} 1] \Leftrightarrow / \check{\mathrm{ej}} /$
b. $[\mathrm{C} 2 \mathrm{P} \mathrm{C} 2] \Leftrightarrow / \check{\mathrm{s}} /$

Finally, let us turn to the lexical entry of $-k$. This suffix can appear either as a Q suffix in the positive, as in (34), or it can spell out the whole complex consisting of $\mathrm{Q}+\mathrm{C} 1+\mathrm{C} 2$ (in the comparative), as in (36).

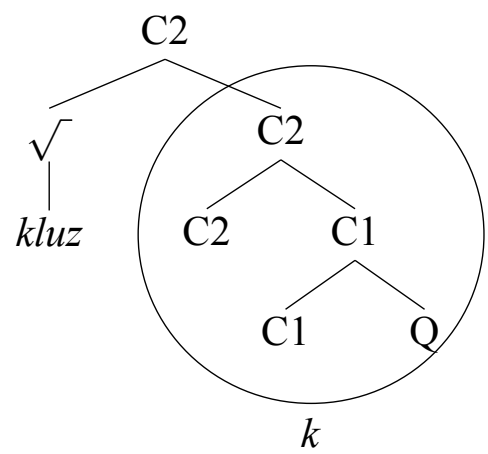

The mechanism by which $-k$ can spell out both Q (as in (32)) and the larger structure dominated by C2 (as in (36)) is again the Superset Principle: taking the lexical entry of $-k$ to be the larger structure, as shown 
in (37), it can 'shrink' to spell out any node that it contains as a constituent. $^{8,9}$

$$
[\mathrm{C} 2[\mathrm{C} 1 \mathrm{Q}]] \Leftrightarrow / \mathrm{k} /
$$

A question that arises at this point is how these structures are created. In particular, looking at the structure in (36) and comparing it to earlier structures as in (34), we see that they contain quite different constituents: (36) has a constituent consisting of $\mathrm{Q}+\mathrm{C} 1+\mathrm{C} 2$ to the exclusion of $\sqrt{ }$, where $\sqrt{ }$ precedes the rest of the terminals, whereas (34) has the $\sqrt{ }$ node at the bottom of the hierarchy, and there is no constituent $\mathrm{Q}+\mathrm{C} 1+\mathrm{C} 2$ to the exclusion of $\sqrt{ }$. In the following section we turn to the details of how these structures are derived from a common underlying functional sequence. ${ }^{10}$

${ }^{8}$ Observe that the lexical item in (37) spells out Q, C1, and C2. A possible alternative consists in assuming that it spells out only Q and $\mathrm{C} 1$, and that $s$ is needed on top of $k$ to spell out $\mathrm{C} 2$. That would amount to the alternative analysis discussed in section 2.1 above, where Standard Czech in fact only has only two allomorphs, and the third (zero marking) reduces to the second (marking by $\breve{s}$ ), modulo phonetically triggered $\check{s}$-deletion. Our proposal is therefore compatible with either analysis.

${ }^{9}$ A reviewer asks if we ever get root $+\mathrm{Q}$ as a synthetic rather than a portmanteau adjective in English. One could think in this respect of a derivational affix like $-y$, which can derive adjectives from nouns (e.g. arty, crappy, skinny, etc.). But there are also quite number of adjectives ending in $-y$, which on the face of it are underived (e.g. nifty, sloppy, silly, pretty, happy, kinky, bonny, busy, canny, phoney). An alternative analysis of these would take them to consist of a root plus $-y$ suffix, in the manner of the Czech $-k$-adjectives.

${ }^{10}$ An anonymous reviewer observes that with some adjectives, like slad- $k-y$ ' 'sweet,' the $-k$ drops in the comparative, yielding slad-š- $i$ 'sweeter.' We see two possibilities for capturing these adjectives. One option is to loosen the containment hypothesis 


\section{Getting technical: the spellout algorithm}

In this section, we make explicit our assumptions concerning the details of how lexical insertion works. While our proposal for splitting the comparative into two heads is to a large extent independent of these assumptions, they will be crucial as the discussion gets more involved. They are also useful for readers to fully understand how in our approach the universal hierarchy of heads is transformed into a language-specific structure with a particular order of the elements. We adopt here the general Nanosyntax approach as developed in recent years by Michal Starke (Starke 2009 et seq.), and specifically we will draw upon the latest additions to the framework as described in Starke (2018). In section 7 we shall propose a nontrivial modification to the framework by eliminating the Elsewhere Principle.

and admit that the comparative does not fully contain the positive (since with these adjectives the comparative form does not contain the positive form). Another option is to rely on pointers, a device which we introduce later on. The behaviour of these adjectives could be captured with the pointer technology by means of a lexical item for slad that consists of $\mathrm{C} 1 \mathrm{P}$ (which makes it incompatible with -ěj), but with a moved root inside the lexical item and a pointer to the $-k$ morpheme at QP-level:

$$
[\mathrm{ClP} C 1[\mathrm{QP}[\sqrt{ }][\mathrm{QP} \rightarrow k]]] \Leftrightarrow \text { slad }
$$

This entry contains the $\sqrt{ }$ node, so it can spell out $\sqrt{ }$. It cannot spell out $\left[\mathrm{Q}^{+} \sqrt{ }\right]$, so in the positive, it needs $-k$. It includes a pointer to this $-k$, so it can spell out a C1P that contains $\mathrm{C} 1$ and a constituent with a root in it and a $-k$ suffix, eliminating both by over-ride, i.e. we get the spellout slad in the comparative. An entry like this, however, raises some technical and empirical issues which we cannot deal in the current paper, so that we leave this issue for future work. 


\subsection{Merge F, Move complement of F}

The first assumption is that structures are built by merging one feature at a time. Every time a new constituent is created by merging a feature, the structure must be lexicalised. A 'lexicalised' structure is one where all its meaningful elements are realised (cf. Fábregas 2007). Still following Starke's work, we adopt here the proposal that only non-terminal nodes can be spelled out (i.e. there is no insertion at a terminal).

Suppose, for instance, that syntax has produced an XP and merged it with the feature F, as in (38a). The lexicon is then consulted, and if it contains a lexical entry which contains the newly formed FP, then the structure is successfully lexicalised. (38b) is an example of such an entry.
a. $[\mathrm{FP} F[\mathrm{XP}]]$
b. $[$ FP F $[\mathrm{XP}]] \Leftrightarrow / \alpha /$

The spellout at FP 'overrides' any prior the spellout of XP; in other words, whatever lexical item was selected for insertion after syntax had constructed XP is no longer considered. This is called 'Cyclic Override' in the Nanosyntactic literature.

Suppose now that the lexicon does not contain (38b), but instead two separate entries, one for $\mathrm{XP}$, and another one for $\mathrm{F}$ and its projection: 

a. $\mathrm{XP} \Leftrightarrow / \beta /$
b. $[\mathrm{FP} F] \Leftrightarrow / \gamma /$

When the lexicon is accessed to see how (38a) can be spelled out, there is no way to spell out FP, since neither (39a) nor (39b) contain the whole FP (including the XP that FP contains), which is required by the Superset Principle. However, since every feature must be lexicalised at every cycle, a repair mechanism is set in motion. Repair mechanisms correspond to various types of movement operations which alter the structure, hoping that lexicalisation will succeed. We will now introduce the various types of movement one by one, and then explain the logic behind their choice.

The first possibility is to move the complement of F out of FP, as shown in (40). This movement option is called rollup or snowball movement, since it takes along anything that is contained in XP.

$$
[\mathrm{FP} \mathrm{XP}[\mathrm{FP} \mathrm{F} t]]
$$

In this new 'repaired' configuration, all the features may be spelled out. XP is realised by (39a), and the lower FP can be lexicalised using (39b) (we assume that traces do not count). ${ }^{11}$

$11 \overline{\text { Various proposals have been made }}$ in the literature as to the precise mechanism from which this follows. The by far simplest assumption is that the movement in (40) does not leave a trace. For concreteness, we keep the trace in the representation for now. 
These two abstract scenarios (direct lexicalisation in (38) and complement movement in (40)) correspond to two derivational options that we need to account for the various classes of Czech comparatives. Direct lexicalisation takes place when we merge $\mathrm{C} 1$ with the positive adjective (QP), as in (41a), and we lexicalise them at once, using an adjective of the size C1P, see (41b).
a. $[\mathrm{C} 1 \mathrm{P} \mathrm{C} 1[\mathrm{QP} \mathrm{Q} \sqrt{ }]]$
b. $[\mathrm{C} 1 \mathrm{P} \mathrm{C} 1[\mathrm{QP} \mathrm{Q} \sqrt{ }]] \Leftrightarrow / \mathrm{star} /$

However, suppose that we want to use a QP-size root; then we cannot lexicalise (41a) directly. We must move QP across C1, as in (42):

$$
[\mathrm{C} 1 \mathrm{P} \mathrm{QP}[\mathrm{C} 1 \mathrm{P} \mathrm{C} 1 t]]
$$

In the configuration (42), all features can be lexicalised. QP is spelled out by the root (with the entry in (43a)), while the lower C1P is spelled out by -ěj (its entry is in (43b)). Note as well that the movement of QP across $\mathrm{C} 1$ also derives the correct suffixal order of exponents, which is the mirror image of the underlying functional hierarchy.
a. $[\mathrm{QP} Q \sqrt{ }] \Leftrightarrow$ /bujar/
b. $[\mathrm{C} 1 \mathrm{P} \mathrm{C} 1] \Leftrightarrow / \check{\mathrm{ej}} /$ 
Suppose now that we add $\mathrm{C} 2$ on top of $\mathrm{C} 1$. Once again, two derivational options arise. Direct lexicalisation (by a root that can spell out C2P) derives zero comparatives:
a. $[\mathrm{C} 2 \mathrm{P} \mathrm{C} 2[\mathrm{C} 1 \mathrm{P} \mathrm{C} 1[\mathrm{QP} \mathrm{Q} \sqrt{ }]]]$
b. $[\mathrm{C} 2 \mathrm{P} \mathrm{C} 2[\mathrm{C} 1 \mathrm{P} \mathrm{C} 1[\mathrm{QP} \mathrm{Q} \sqrt{ }]]] \Leftrightarrow /$ ostřr

If a root is not large enough, snowball movement of C1P across C2 is triggered, and $\mathrm{C} 2 \mathrm{P}$ is spelled out as $-\check{S}$ :
a. $[\mathrm{C} 2 \mathrm{P}[\mathrm{C} 1 \mathrm{P} \ldots][\mathrm{C} 2 \mathrm{P} \mathrm{C} 2 t]]$
b. $[\mathrm{C} 2 \mathrm{P} \mathrm{C} 2] \Leftrightarrow / \check{\mathrm{s}} /$

The spellout of C1P is marked by three dots in (45a), because it is variable (as has already been discussed). Specifically, C1P may either be lexicalised directly by a root like star 'old,' in which case we derive the $-\check{S}$ comparative. Alternatively, there may be movement inside C1P (see (42)), in which case we derive the $-\check{e} j-s ̌$ comparative.

Notice finally that if a given root has a lexical entry that allows it to spell out C1P directly, then it will always do so. This suggests a hierarchy of operations, where movement is a last resort: only if direct lexicalisation fails does movement apply. Without such a hierarchy, the system would be able to spell out C1P as *stař-ej instead of star 'old', 
which is clearly an undesirable result. Therefore, the two spellout options discussed so far must be ranked in a spell-out algorithm as follows:

\section{Spell-out Algorithm (v1, preliminary), Starke (2018)}

a. Merge F and spell out.

b. If (a) fails, move the complement of $F$, and spell out.

The spell-out algorithm, combined with the lexical entries in (47), allows us to derive three of the patterns observed, namely bujař-ej-šs 'merrier', star-šs 'older', and ostř- 'sharper,' with the lexical entries specified as follows:
a.
$\left[\mathrm{QP} Q \sqrt{ }{ }^{-}\right] \Leftrightarrow$ /bujar/
b. $[\mathrm{C} 1 \mathrm{P} \mathrm{C} 1[\mathrm{QP} \mathrm{Q} \sqrt{ }]] \Leftrightarrow / \mathrm{star} /$
c. $[\mathrm{C} 2 \mathrm{P} C 2[\mathrm{C} 1 \mathrm{P} C 1[\mathrm{QP} Q \sqrt{ }]]] \Leftrightarrow / \mathrm{ostr̆} /$
d.
$\Leftrightarrow \quad / \mathrm{e} \mathrm{j} /$
e.
$\Leftrightarrow \quad / \check{\mathbf{s}} /$

Now we turn to how complex adjectives like $k l u z-k$ 'slippery' are derived. 


\subsection{Move spec-to-spec}

In order to obtain the correct forms of these adjectives, we must introduce yet another type of repair strategy: spec-to-spec movement. This repair strategy does not remove the whole complement of the newly added F, but only the Spec of the complement. In Starke (2018), the operation occupies a fixed place in the hierarchy of repairs as given in (48):

(48) Spell-out Algorithm (v2, preliminary)

a. Merge F and spell out.

b. If (a) fails, try spec-to-spec movement of the node inserted at the previous cycle, and spell out.

c. If (b) fails, move the complement of F, and spell out.

We will comment on the ordering of the operations shortly, but first we want to show how the new derivational option works on its own. Let us then go back to (40), which represents the stage of the derivation where XP extracts out of FP. Suppose we now continue the derivation by adding a new feature, F2 (for clarity, we rename F to F1):

[F2P F2 [F1P XP [F1P F1 $t]]]$ 
Suppose now that we have a lexical entry like in (50), i.e. one that spells out both F1 and F2:

$$
[\mathrm{F} 2 \mathrm{P} F 2[\mathrm{~F} 1 \mathrm{P} F 1]] \Leftrightarrow / \delta /
$$

This lexical entry cannot spell out (49), since (50) does not contain (49). Hence, movement must take place. In this particular case, what is needed in (49) is to move the XP (i.e. the highest Spec of the complement of F2) out of F2P, as shown in (51). Here the XP has been cyclically moved from the complement of F1 to its Spec, and then further on to Spec,F2P:

$$
[\mathrm{F} 2 \mathrm{P} \text { XP [F2P F2 [F1P } t[\mathrm{~F} 1 \mathrm{P} \mathrm{F} 1 t]]]]
$$

F2P can now be spelled out as $/ \delta /$ using (50), since the structure is identical to the lexical entry (ignoring traces).

A specific example of this strategy is the derivation of $-k$ adjectives. Recall that the lexical entry for $-k$ is as follows:

$$
[\mathrm{C} 2 \mathrm{P} \mathrm{C} 2[\mathrm{C} 1 \mathrm{P} \mathrm{C} 1[\mathrm{QP} \mathrm{Q}]]] \Leftrightarrow / \mathrm{k} /
$$

When deriving the QP (the positive degree of such adjectives), we combine the $\mathrm{Q}$ head with the $\sqrt{ }$, see (53a). For roots (like $k l u z$ ) that are not adjectival, i.e. do not spell out QP, we cannot spell out (53a) without 
movement. We thus move the $\sqrt{ }$ across $Q$, as shown in (53b), and spell out QP by $-k$. The derivation now continues by merging $\mathrm{C} 1$, as in $(52 \mathrm{c})$. This structure cannot be spelled out without movement, and hence, $\sqrt{ }$ moves on by spec-to-spec movement, yielding (52d).
a. $[\mathrm{QP} \mathrm{Q} \sqrt{ }]$
b. $[\mathrm{QP} \sqrt{[\mathrm{QP}} \mathrm{Q} t]]$
c. $[\mathrm{C} 1 \mathrm{P} \mathrm{C} 1[\mathrm{QP} \sqrt{[\mathrm{QP}} \mathrm{Q} t]]]$
d. $\quad[\mathrm{C} 1 \mathrm{P} \sqrt{ }[\mathrm{C} 1 \mathrm{P} \mathrm{C} 1[\mathrm{QP} t[\mathrm{QP} \mathrm{Q} t]]]]$

Here the remnant $\mathrm{C} 1 \mathrm{P}$ is spelled out by $-k$, which has thereby pronounced the projection of $\mathrm{C} 1$ that would, on its own, be pronounced as $-\check{e} j$. This is the correct result, since the comparative of the $-k$ derived adjectives definitely lack this marker, regardless of whether they do or do not have the comparative $-\check{s}$.

This derivation also gives us reasons to rank the spec-to-spec movement higher than the movement of the whole complement. Suppose that instead of moving spec-to-spec as shown in (53d), we first moved the complement of $\mathrm{C} 1$, producing (54) as the first attempt, after failing to spell out (53c):

$$
[[\mathrm{QP} \sqrt{ }[\mathrm{QP} \mathrm{Q} t]][\mathrm{C} 1 \mathrm{P} \mathrm{C} 1 \mathrm{t}]]
$$


In this structure, $\mathrm{C} 1 \mathrm{P}$ gets spelled out by $-\check{e}$, which would follow in the string after the root and the $-k$ suffix, deriving the incorrect $k l u z-k$-ěj . If this was the first attempt at a repair structure, all the relevant features would be spelled out, and there would be no motivation for trying another repair strategy. In other words, $k l u z-\check{c}-e j$ (after palatalisation) would block the correct output kluz-k. In order to avoid this, we have to rank spec-to-spec movement before complement movement. This result provides an empirical support for the proposal in Starke (2018), who considers spec-to-spec movement more economical on the grounds that it carries less material.

The spellout algorithm in (48) applies recursively, i.e. after each successful spellout, the entire procedure in (48) is repeated. We shall return to the formulation of the spellout algorithm in section 5 below, where we discuss markers of the comparative that precede the adjective. These are not accommodated under the current formulation in (48) above, and will require a further extension of it. However, before discussing such cases, we turn to some new data.

\section{Comparatives in Old Church Slavonic}

This section turns to comparatives in Old Church Slavonic (OCS). OCS is the oldest Slavic language attested in writing (9th century). Even though it is not a direct ancestor of Czech, it clearly exhibits much of 
the same patterns, demonstrating their diachronic stability. More importantly, it also features facts that may look problematic for our approach to zeroes, as pointed out to us by an anonymous reviewer, with reference to Bopp (1833). However, we think that if these facts are properly analysed, there is no counterexample to our analysis coming from OCS.

Let us start by looking at the GEN.SG form of the comparative, since it is more characteristic of the entire paradigm than the nominative and the accusative, which show some special properties; we discuss the latter case forms next. OCS is like Czech in that it has root-controlled allomorphy. The table in (55) shows two such allomorphs: one is found with the adjective bol- 'big' (in the first row), the other with nov- 'new' (in the second row). According to Aitzetmüller (1978:131-2) and Lunt (2001:77-8), these are the only two types of comparatives in OCS. ${ }^{12}$

$$
\text { Two types of adjectives in OCS (Aitzetmüller 1978:131-2) }
$$

\begin{tabular}{ccccc} 
& M & N & F & gloss \\
\hline GEN & bol- jьš-a & bol- jьك̌-a & bol- jьš-ę & 'bigger' \\
GEN & nov-ě-jьš-a & nov-ě-jьš-a & nov-ě-jьš-ę & 'newer'
\end{tabular}

These data are amenable to an analysis that is virtually identical to modern Czech: the marker $\check{e}$ spells out $\mathrm{C} 1, j b \check{s}$ spells out $\mathrm{C} 2$. The root bol-is specified as C1P, which leads to the disappearance of $-\check{e}$ on the surface.

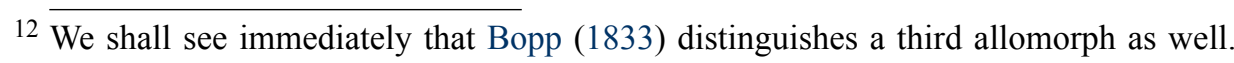
The grapheme b corresponds to a 'reduced' vowel $\mathrm{i}$, sometimes written as $\breve{1}$. 
However, things get more complicated when we look at full paradigms which include the nominative and the accusative. We start from the adjective 'newer.' This adjective has a bi-morphemic comparative in (55), with separate markers for $\mathrm{C} 1$ and $\mathrm{C} 2$ present. However, in the following table, the C2 marker $-j b \check{s}$ remains silent in the shaded cells. ${ }^{13}$

'Newer' in Old Church Slavonic (Aitzetmüller 1978:132)

\begin{tabular}{|c|c|c|c|}
\hline & M & $\mathrm{N}$ & $\mathrm{F}$ \\
\hline NOM & nov-ě- jь & nov-ě- je & nov-ě-jьš-i \\
\hline ACC & nov-ě-jьš-ь & nov-ě- je & nov-ě-jьš-Q \\
\hline GEN & nov-ě-jbš-a & nov-ě-jbš-a & nov-ě-jbš-ę \\
\hline LOC & nov-ě-jьš-i & nov-ě-jьš-i & nov-ě-jbš-i \\
\hline DAT & nov-ě-jbš-u & nov-ě-jbš-u & nov-ě-jьšs-i \\
\hline INS & nov-ě-jьš-emь & nov-ě-jьš-emь & nov-ě-jьš-ejQ \\
\hline
\end{tabular}

This is apparently problematic for our generalisation in (20), which claims that zero markers spread from the root out. However, as with the comparative adverbs, the crucial point is that our generalisation in (20) regulates root-controlled zeroes, and the $\mathrm{C} 2$ zeroes in (56) do not belong to this category. Rather than a specific root, it is a particular combina-

13 There is an alternative segmentation/analysis of these forms, namely one where the inflectional endings in the shaded cells are just $-b /-e$, in which case the preceding $j$ would be a leftover of the $\mathrm{C} 2$ comparative marker. In such case, we would need to split $\mathrm{C} 2-j b \check{s}$ into $\mathrm{C} 2 \mathrm{a}-j$ and $\mathrm{C} 2 \mathrm{~b}-b \check{s}$, and propose an analysis according to which only $\mathrm{C} 2 \mathrm{~b}$ goes missing. This analysis is viable, but we shall not develop it further in this paper. 
tion of $\varphi$-features (whose markers immediately follow C2) which is to be blamed for the absence of an overt $\mathrm{C} 2$ exponent. We therefore propose that in these cases, the absence of $\mathrm{C} 2$ is not due to phrasal spellout by the root (which clearly does not control this effect), but due to the fact that the ending, which expresses a particular $\varphi$-feature combination, spells out [C2+agr]. This is shown in (57), with roll-up movement of QP across C1, and then cyclic spec-movement of C1P to the left of AGR. ${ }^{14}$

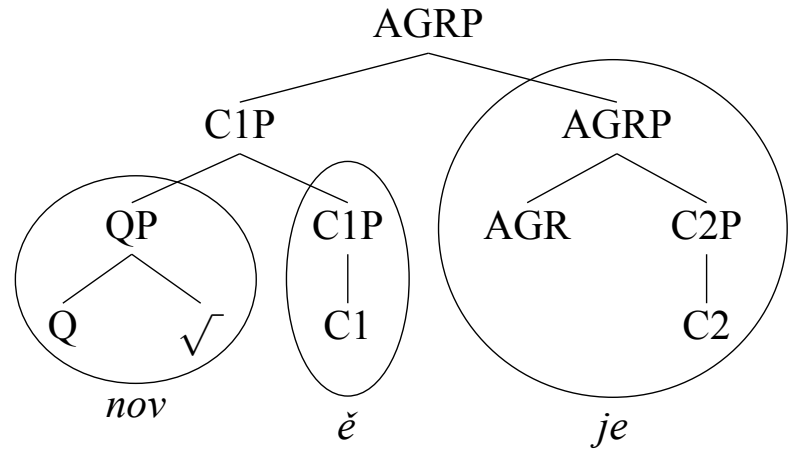

This shows that our analysis in fact allows for a 'zero' $\mathrm{C} 2$, even if $\mathrm{C} 1$ is non-zero, but only in case the zero spellout of $\mathrm{C} 2$ is conditioned by outside morphology, and not by the root. ${ }^{15}$

$14 \overline{\text { AGR is in fact internally complex, }}$-je being a portmanteau for gender, number and case. We abstract away from this complication since it is orthogonal to our concerns.

${ }^{15}$ It is worth noting that the Czech adverbs, which realise $\mathrm{C} 1-\check{e j}$ but not $\mathrm{C} 2-\check{S}$ (see (18) above), share this property of an affix-controlled zero. Diachronically, they are the continuation of the neuter forms shown in (56). Their analysis is perfectly analogous to (57), substituting ADV for AGR. 
This analysis is confirmed by the behaviour of the adjective 'bigger.' In (58), we give its full paradigm. The most telling contrast is between the ACC of the masculine and neuter paradigms. Here one can clearly see that the neuter has neither $\mathrm{C} 1 \check{e}$ (as this gets realised by the root), nor $\mathrm{C} 2-j b \check{s}$, since this morpheme gets eaten by agr $-j e$. 'Bigger' in Old Church Slavonic (Aitzetmüller 1978:131)

\begin{tabular}{|c|c|c|c|c|c|}
\hline & \multicolumn{2}{|r|}{ M } & \multicolumn{2}{|r|}{$\mathrm{N}$} & $\mathrm{F}$ \\
\hline NOM & bol- & јь-јь & bol- & je & bol- jbš-i \\
\hline ACC & bol- & jьš-jь & bol- & je & bol- jьك̌- $Q$ \\
\hline GEN & bol- & jbš-a & bol- & jbš-a & bol- jьš-ę \\
\hline LOC & bol- & jьš-i & bol- & jьš-i & bol- jьš-i \\
\hline DAT & bol- & јьš-u & bol- & jьš-u & bol- jbš-i \\
\hline INS & bol- & jьš-emь & bol- & jьš-emь & bol- jьš-ejc \\
\hline
\end{tabular}

The analysis of the NOM/ACC neuter forms is shown in (59).

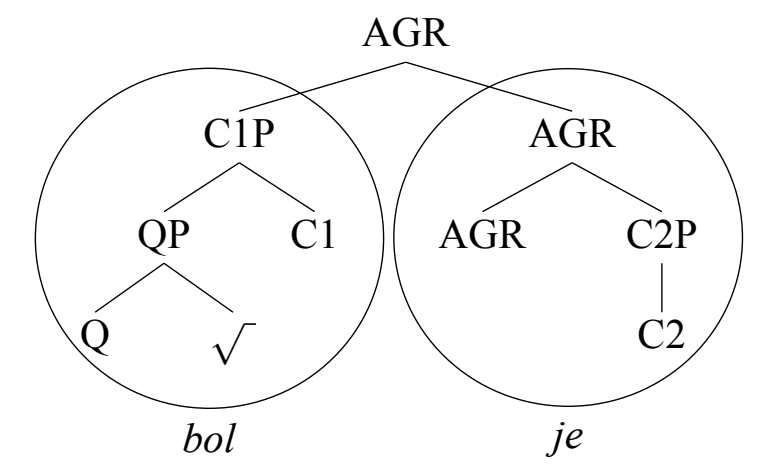


This form then confirms that the disappearance of $\mathrm{C} 2$ is a process that is completely independent of the particular root, because all roots lose $\mathrm{C} 2$ before the relevant endings, exactly as predicted by the current account. ${ }^{16}$

The second issue we want to address here is the development from the OCS type of system to the Czech type of system. A part of this change can be understood as a relatively straightforward case of paradigm levelling. In particular, during the Early Old Czech, "under the influence of the feminine and the oblique cases, there appeared [in the shaded cells of (58) ] an analogical suffix $-\check{s} i$, which was in complementary distribution with ějšì" (Lamprecht et al. 1986:313, translation from Czech is ours). In our system, this change corresponds to a change in the lexical entries of the agreement markers, which now fail to spell out $\mathrm{C} 2$, leaving C2 to be spelled out by $\check{s}$, as in the other cases and genders. This devel-

16 The only remaining issue is the form of the NOM.SG.M which has the ending $-j b-j b$, and not the expected $-j b$. As far as we could determine, this is an effect of declension type. Specifically, OCS has two different adjectival declensions, an indefinite one, which we present in the declension tables, and a definite one. The definite declension is derived from the indefinite one by the addition of a pronoun. For instance, from the indefinite bol-je 'bigger, N' one derives bol-je-je 'bigger, N-DEF'. However, in the comparative only, the definite masculine form is the same as the indefinite one, namely $b o l-j b-j b$, a form which morphologically resembles the definite paradigm by the 'doubling' of the inflection. In sum, we think that the M.sG. cell shows a definite form for reasons that are unclear to us, yet this seems to be already remarked in Bopp (1885:409), who claims that "comparatives always follow, in the masculine and neuter, the definite declension." In accordance with this statement, Bopp also gives the neuter in je-je, which the later grammars give as the indefinite with a single-je, while keeping the double $j b-j b$ in the masculine. 
opment led to the present day paradigms with -ějšsi and -šs throughout the paradigm, as illustrated in the first two columns of (60).

(60) Levelled paradigms in Czech, neuter forms

\begin{tabular}{cccl} 
& 'newer' & 'better' & 'thinner' \\
\hline NOM & nov-ěj-š-í & lep-š-í & ten-č-í \\
ACC & nov-ěj-šsí & lep-š-í & ten-č-í \\
GEN & nov-ěj-š-ího & lep-š-ího & ten-č-ího \\
LOC & nov-ěj-šs-ím & lep-š-ím & ten-č-ím \\
INS & nov-ěj-š-ím & lep-š-ím & ten-č-ím \\
DAT & nov-ěj-šśímu & lep-š-ímu & ten-č-ímu
\end{tabular}

However, this leaves it unexplained why there are three comparative allomorphs in Czech. In particular, how did the $-\varnothing$ allomorph, an example of which is seen in the third column, arise? According to Kosek (2014:131-2), this paradigm is to be interpreted as a case where paradigm levelling proceeded in the opposite direction, and the oblique forms were attracted to the nominative. He writes: "during the development of Old Czech in the middle period, an a-historical way of comparative formation by the suffix $-i$ came to existence. This new type of comparative marking represents the emancipation of the original M.NOM.SG form" (translation ours). 
What happened, then, is that in some cases, all the case forms levelled in the direction of the NOM.SG (nonfeminine). However, the NOM.SG had no comparative marker, and since the endings could not have been analysed as spelling out the comparative $\mathrm{C} 2$ any longer (as this was impossible in the other classes, which had the same agreement markers plus the $\mathrm{C} 2$ marker $\breve{s}$ ), the only option was to analyse the paradigm in a way that it was the root which spelled out both $\mathrm{C} 1$ and $\mathrm{C} 2$. In sum, different directions of paradigm levelling led to the result that a new class of comparatives was born. ${ }^{17}$

The final point we want to turn to is a comment on the analysis of OCS presented in Bopp (1833), brought to our attention by an anonymous SL reviewer. The first thing to note is that Bopp (1833:421-6) (unlike the later grammarians) distinguishes not two, but four different ways of marking the comparative. The masculine singular forms of Bopp's four allomorphs are given in the table (61). The rows correspond to our well-known distinction between two types of roots: those that spell out $\mathrm{C} 1$ are on the first row, those that fail to spell out $\mathrm{C} 1$ are on the second row. In Bopp's work, this two-way distinction is cross-cut by an additional distinction, namely whether $\mathrm{C} 2$ is overt or not. In the left column (labelled 'C2 zero'), we find the forms that we are already

17 It is worth noting here that in the genetically closely related language Polish there was an evolution toward a system where the distribution of the two allomorphs (-ejsz $(y)$ and $-s z(y)$ ) is phonologically conditioned (Rubach 1986:272; Bethin 1987; Szpyra 1992:286). 
familiar with from Aitzetmüller (1978). Here, as we have proposed, the agreement markers spell out $\mathrm{C} 2$. In the second column (labelled ' $\mathrm{C} 2$ overt'), we find two new forms where $-(j b) \check{s}$ appears to the immediate left of the agreement marker. The segmentation of the forms is ours, agreement in brackets.

OCS NOM.SG.M according to Bopp (1833:421-6) ${ }^{18}$

\begin{tabular}{|c|c|c|}
\hline & C2 zero & $\mathrm{C} 2$ overt \\
\hline C1 zero $(\sqrt{b o l-})$ & $(-j b-j b)$ & $-\check{s}(-j b-j b)$ \\
\hline $\mathrm{C} 1$ overt $(\sqrt{n o v}$ & -ě $(-j b)$ & -е̌-jьšs(-jь-jь) \\
\hline
\end{tabular}

When we look at the new forms in the final column with the knowledge of the later development of the OCS comparative, it seems that Bopp's allomorphs with $-\check{S}$ are not special independent allomorphs of the comparative, but rather the harbingers of paradigm levelling. This interpretation of Bopp's forms with $-\check{S}$ is supported by the fact that the

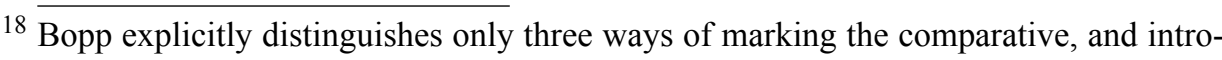
duces the fourth way (е̌-jь) as a sub-paradigm of $j b-j b$, even though the two markers do not appear on the same roots. He also uses slightly different transcription, shown in (i).

(i)
$\begin{array}{lll}M & F & N\end{array}$

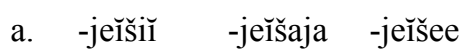
b. -šiı $\quad-$ šaja $\quad$ šee

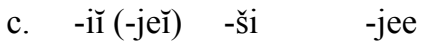

Here Bopp's je corresponds to Aitzetmüller's $\check{e}$, Bopp's $\breve{l}$ and $i$ correspond to Aitzetmüller's $j b$. Bopp's $-\check{s}$ initial suffixes in (ib) are rendered as $-j b \check{s}$ in Aitzetmüller $(-b \check{s}$ in Lunt), which unifies the two distinct $-\check{S}$ forms in (61). 
forms on the first row are illustrated by one root (Bopp gives $u n(-j b-j b)$ well as $u n-\check{s}(-j b-j b)$ 'better, M.SG'), while the forms on the second row

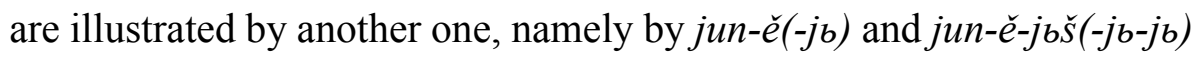
'younger, M.SG.'

Being primarily interested in the origin of these forms, Bopp hypothesised that the form in the bottom right corner (-ějbšjbjb) could be

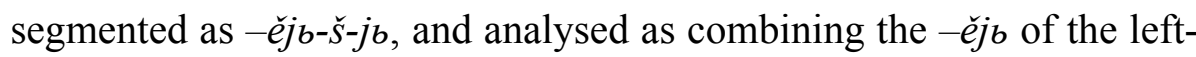
bottom cell, and the $-\check{s}-j b-j b$ of the top right cell. If this analysis was correct, it would entail that the -ějb form in its entirety is C1, with C2 radically missing. As an anonymous reviewer points out, this would be problematic for our claims.

For reasons that were made clear above, we do not think that this problem is real. The reason is that Bopp's analysis of the forms is rather superficial. Firstly, he ignores the fact that the variation in the table is split along two dimensions. As a consequence, he assumes that the in-

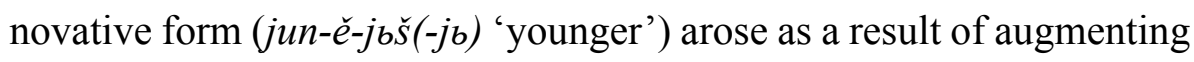
its old form jun-ěe(-jb) with a marker of the innovative shape belonging to a different root class. This completely misses the logic of a parallel development where both root classes simply adjusted their nominatives to the rest of the paradigm (a fact that Bopp fails to see, for he only looks at the nominative forms). In addition, Bopp in effect suggests that the whole old ending $-\check{e}-j b$ corresponds to an invariant $\mathrm{C} 1$ in all gen- 
ders and numbers, which seems unrealistic, given that $-j b$ in $j u n-\check{e}-j b$ is a M.SG ending (as Bopp himself admits). For all these reasons, we do not think that Bopp's reasoning represents a valid base for rejecting our claim that there are roots which require the pattern with $\mathrm{C} 1$ overt and C2 silent. This conclusion seems to have been also adopted in the later descriptive tradition (Aitzetmüller 1978:131-2 and Lunt 2001:778), who rejected the innovative forms as such, and removed them from the descriptions.

An important take-home message is that many of the same patterns that we find in present-day Czech have been part of the language for more than a thousand years, demonstrating the robustness and stability of the "double comparative" marking. Also, we have seen that there are circumstances under which $\mathrm{C} 2$ may be silent, even when $\mathrm{C} 1$ is present, which we predict to arise only in case C2's zero exponence is triggered by an inflectional marker higher up in the structure, as is the case in OCS. Finally, we acknowledge here Bopp's thinking as a precursor to our ideas, though we are not sure that the reasons that led him to his "double comparative" analysis are correct. 


\section{English comparatives}

\subsection{The issue}

The theory outlined so far leads to an expectation that more languages will exhibit a difference between two types of adjectival roots, which differ in their size. In this section, we argue that the difference between -er and more comparatives in English can be captured along these lines, which leads to an interesting prediction about suppletion, to be explored in the next section. Specifically, following Corver (1997); Bobaljik (2012), we will analyse more as a complex marker, since it is the comparative form of much. Building on this observation, we can establish the following (tentative) Czech-English correspondence table, where we draw a parallel between the Czech complex marker -ěj-š and the English more, as well as a parallel between the simplex comparatives:

\begin{tabular}{|c|c|c|}
\hline$\sqrt{ }$ & $\mathrm{C} 1$ & $\mathrm{C} 2$ \\
\hline bujar & ěj & $\check{\mathrm{S}}$ \\
\hline \multicolumn{2}{|l|}{ star } & $\check{\mathrm{s}}$ \\
\hline intelligent & mo & re \\
\hline \multicolumn{2}{|l|}{ old } & er \\
\hline
\end{tabular}

In the table, we have decomposed more into two pieces, but it may also be considered an opaque piece of morphology realising both $\mathrm{C} 1$ and C2. The proposal we are about to develop is independent of the surface 
decomposability of more, and we will in fact adopt a proposal where more is a portmanteau for $\mathrm{C} 1$ and $\mathrm{C} 2$.

As a result of attributing different complexity to the two different comparative markers ( $\mathrm{C} 2$ for $-e r, \mathrm{C} 1+\mathrm{C} 2$ for more), and assuming that the underlying structure of the two classes of comparatives is the same, we automatically arrive at different lexical specifications of the roots which combine with these markers. Specifically, roots like intelligent are specified as a QP, while roots like old are specified as C1P. The result is a theory where the selection between a root and a particular comparative marker is a consequence of different root size. ${ }^{19}$

Based on the theory we have laid out in section 3, we can straightforwardly express the parallel between Czech and English in the form of tree representations. What we are proposing here is that English comparatives also involve two comparative heads. In comparatives expressed by $-e r$, the suffix spells out a single feature (C2), and the whole class is thus analogous to $\check{s}-i$ comparatives in Czech. In order to bring out the

19 A lexical approach to the distinction between morphological and periphrastic comparatives in English is also taken by Bobaljik (2012); Gouskova \& Ahn (2016), among others. This is not to deny that there might be certain phonological or other regularities governing the choice for either option. There is in fact an extensive literature on this issue, which has identified a range of factors relevant to the choice, such as the frequency of the adjective, as well as a variety of phonological factors (see e.g. Jespersen 1954; Aronoff 1976; Quirk et al. 1985; Culpeper \& Leech 1997; Graziano-King 1999; Mondorf 2003; Graziano-King \& Smith Cairns 2005; LaFave 2005; Hilpert 2008; Mondorf 2009; Bobaljik 2012; Matushansky 2013; Enzinna 2017). 
parallel, we have simply placed the Czech lexical items for the comparative 'old-er' alongside the English lexical items.

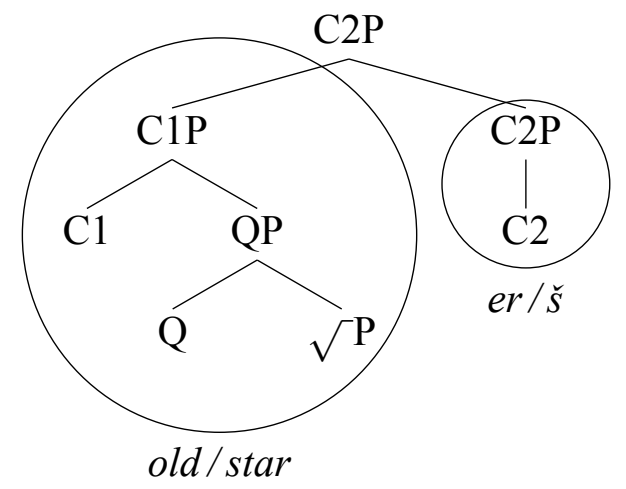

For the English analytic comparatives, however, a different structure is needed than for the Czech - $\check{e} j-\check{s}-\dot{\imath}$ comparatives, despite the fact that both $-\check{e} j-\check{s}-i$ and more combine with roots of the QP size. If we simply specified more for the features $\mathrm{C} 1$ and $\mathrm{C} 2$, similarly to the Czech suffix $-k$ in (37), we would expect that the root would have to move to the left of more (deriving *intelligentmore), just like in Czech the root moves to the left of $-k$. In order to satisfactorily address this issue, we need to return to the spellout algorithm, and extend it to account for comparative markers preceding the adjectival root.

\section{2. $\operatorname{Merge}(X, Y)$}

Recall from section 3 above that in our system, all suffixes arise due to complement extraction. This is shown in (64), where the complement 
of $\mathrm{F}$ has moved up, landed at a place indicated by the dots, and left just a single branch inside $\mathrm{FP}^{20}$

(64) $\quad[\ldots[\mathrm{FP} F]$

Lexical items in our system are simply links between a well-formed syntactic structure and its pronunciation. Therefore, lexical entries for suffixes will naturally copy this tree-shape, and always contain a nonbranching FP as their lowest ingredient. However, this option does not exhaust the logical possibilities of what a syntactic structure may look like, and by the same token, what a lexical entry may look like. In particular, a lexical entry can also correspond to a syntactic object created by the merger of two features, as in (65). Ultimately, this will be a type of entry which we will use for prefixes, and we will now work towards clarifying the reasoning behind this conclusion.

[F2P F2 F1 ]

We start from the observation that the entry (65) spells out a node (F2P) out of which nothing has been extracted. Such structures may correspond to various objects in the 'real world,' depending on the overall structure of the syntactic theory. The least controversial use of such lex-

20 From here on, we shall omit traces. Since their presence may be inferred from the nonbranching projecting structure $[\mathrm{FP} F]$, that structure serves as the equivalent of one with a trace. 
ical entries is when they correspond to roots. For instance, in Bobaljik (2012), an example of such an entry is when [A + CMPR $]$ are spelled out together, which corresponds for instance to a suppletive comparative root like worse. In our system, a root like bujar 'merry' realises [Q $+\sqrt{ }]$, which also corresponds to a syntactic object of the type in (65).

Such (internally) complex roots may of course move (by spell-outdriven movement, for instance), and then they end up in the specifier of a functional head, as in (66), where F2P is the phrase corresponding to (65), and F3 is the functional head in whose Spec it resides after movement from its complement.

\section{(66) $\quad[$ F3P F2P [F3P F3 ]]}

The placement of F2P into the Spec of F3P does not contribute anything to the meaning composition, which is reflected by the fact that the specifier does not project, and F3 remains the head of the whole phrase. However, Starke (2004) proposes that in addition to such 'nonprojecting' specifiers, there are also 'projecting' specifiers. Projecting specifiers are like heads in that they contain features inside them that contribute to the building of the main projection line, but which at the same time are internally complex. Starke (2004) discusses wh-phrases as a case in point, and such structures have recently been used in Caha \& 
Pantcheva (to appear) or Taraldsen et al. (2018) to deal with classifiers in Bantu.

To approximate the idea on Indo-European data, consider, for instance, the Norwegian word kopp 'cup.' It has a use as an ordinary noun, referring to an object. However, it also has a classifier use. Specifically, in Norwegian, one may say en kopp kaffe, literally 'a cup coffee' (without of), where kopp resembles a functional head, which partitions the mass denotation of coffee into units containing the quantity defined by the classifier. However, even when used as a classifier, kopp retains nominal characteristics. First of all, it defines the relevant QUANTITY by reference to the prototypical size of a THING, namely a cup. This can be captured if cup has a lexical entry [ QUANT $\mathrm{N}$ ]. The presence of $\mathrm{N}$ inside the classifier (which overlaps with that of coffee) is confirmed by its formal behaviour: it controls agreement on adjectives that are placed higher up in the structure.

A projecting Spec is thus a phrasal object, which contributes to the meaning composition and provides its label to the whole structure, as in (67). Such a structure may also allow for a (partial) overlap in features between the Spec and the root (both have F1). 


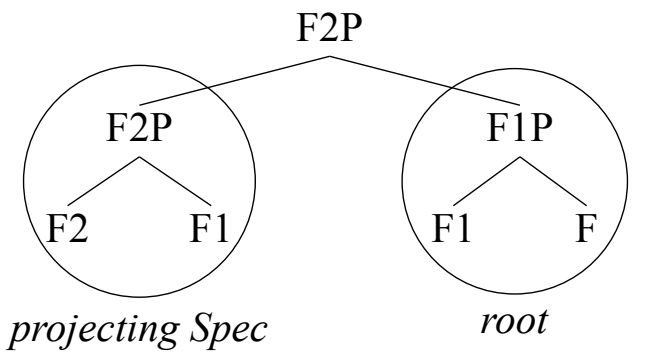

We further adopt the proposal by Starke (2018), which says that such projecting Specs correspond not only to separate words, but also to prefixes.

With the background clarified, let us now turn to the issue of how the formation of a projecting Spec fits into the overall architecture of a theory based on spellout-driven movement. Obviously, constructing a complex Spec presupposes that we create the Spec in a separate derivational workspace, and only then add it to the main projection line.

Let us consider an abstract example of a derivation with such a projecting Spec in the form of a prefix. Suppose that we have added the feature F3 to a phrase containing F2 and F1, as in (68a). Suppose that F2P spelled out successfully as $\beta$ given the lexical item in (68b), and further that the only entry containing F3 is the one in (68c).
a. [F3P F3 [F2P F2 F1 ] ]
b. $[\mathrm{F} 2 \mathrm{P} F 2 \mathrm{~F} 1] \Leftrightarrow \beta$
c. $[$ F3P F3 F2 $] \Leftrightarrow \alpha$ 
In such a scenario, the spellout of F3P would fail no matter what movement we try. If we extracted the complement of F3, we would need to spell out the boldfaced constituent in (69a). However, this syntactic constituent is not identical to any node contained in the entry (68c). \\ a. [F3P [F2P F2 F1 ] [F3P F3 ] ] \\ b. [F3P [ F1 ] [F3P F3 [F2P F2 ]] ]}

Similarly, if we extracted the complement of F2, F1, raising it to adjoin to F2P, and subsequently applied spec-to-spec movement to yield (69b), we would have to spell out the boldfaced constituent in (69b). This constituent does contain only the features F3 and F2 (like the entry (68c)), but what is required for spellout in Starke (2009) is that the lexical entry contains a constituent that is fully identical to the syntactic structure. In (69b), the non-branching node above F2 makes the structure different from $(68 \mathrm{c})$.

What we then need to do is to add F3 not as a single feature, but bake it into a complex Spec by starting a new derivation that will merge F3 with some other feature. Which feature is this going to be? The two most salient options are either the next feature higher up (F4), or the next feature lower down (F2). If we choose the former option, we end up with a Spec consisting of F4 and F3. This is sub-optimal, since this way we may be forced to merge more features than we actually 
want, like F4 in the above example. A more concrete case would be one where, for instance, we want to merge the gradability feature $Q$, and the only way to do it is to add it as a part of a complex Spec. If we defined things in a way that $\mathrm{Q}$ has to merge with the next feature higher up, we would have to add $\mathrm{C} 1$ to $\mathrm{Q}$. But such a result is unusable, since we would derive a (semi-)comparative instead of a positive. Formulated more generally, if a Spec spawned by the need to spell out $\mathrm{F}$ always adds $\mathrm{F}$ and $\mathrm{F}^{+1}$, unwanted results arise. Therefore, we suggest that a new derivation spawned by the need to spell out $\mathrm{F}$ always merges $\mathrm{F}$ with $\mathrm{F}^{-1}$, and that it is this combination that is the first thing the system constructs after opening the new workspace.

We further assume that before $\mathrm{F}$ is used to start a new derivation, it is removed from the main derivation, since it cannot get spelled out there. We follow Starke (2018) in considering complex Spec formation as the absolute last resort, which is tried only after everything else fails. All of this is integrated into the spellout algorithm in (70).

Spellout Algorithm (v3, preliminary)

a. Merge F and spell out.

b. If (a) fails, try spec-to-spec movement of the node inserted at the previous cycle, and spell out.

c. If (b) fails, move the complement of F, and spell out. 
d. If (c) fails, remove $F$ from the main workspace, merge it with $\mathrm{F}^{-1}$ and spell out.

The result of the algorithm is that if it comes to (70d), we end up with two workspaces, one old, the main projection line, and the other freshly created. Both can be spelled out, but they are not integrated together. As to when exactly should the two workspaces be joined again, is a topic of ongoing research. Nevertheless, a simple implementation which works well for the purpose of this paper is that the second workspace remains open and subject to further merge F operations only as long as the Spec spells out as one piece. Once we would need to do movements within the Spec, the workspace is closed and the Spec integrated with the main workspace. This is the content of $(71 \mathrm{~b})$, which we add as a new and final step in the formulation of the spellout algorithm.

\section{Spellout Algorithm (final version)}

a. Merge F and spell out

b. If (a) fails in the second workspace, undo merge F, and close the workspace by merging it with the main derivation

c. If (a) fails in the first workspace, try spec-to-spec movement of the node inserted at the previous cycle, and spell out.

d. If (b) fails, move the complement of F, and spell out. 
e. If (c) fails, remove $\mathrm{F}$ from the first workspace, merge it with $\mathrm{F}^{-1}$ in a second workspace, and spell out.

With the theory in place, we turn back to comparatives with more.

\subsection{Analytic comparatives}

Recall that in our analysis, adjectives which combine with the comparative marker more are simple gradable adjectives, i.e. they spell out QP. They differ from adjectives which mark the comparative suffixally, which spell out C1P:

$$
\begin{array}{llll}
\text { a. } & {[\mathrm{QP} \mathrm{Q} \sqrt{ }]} & \Leftrightarrow & \text { /intelligent/ } \\
\text { b. }[\mathrm{C} 1 \mathrm{P} \mathrm{C} 1[\mathrm{QP} \mathrm{Q} \sqrt{ }]] & \Leftrightarrow & \text { /old/ }
\end{array}
$$

$$
[\mathrm{C} 2 \mathrm{P} \mathrm{C} 2] \Leftrightarrow / \text {-er/ }
$$

Given that -er only spells out C2, (72) correctly encodes the fact that the root intelligent cannot combine with $-e r$ to form a comparative, since neither the root nor the suffix spell out $\mathrm{C} 1$. In the analysis we propose, the $\mathrm{C} 1$ feature is present in the lexical entry for more. What does this entry look like beyond having $\mathrm{C} 1$ ?

Recall that in the theory of spellout-driven movement that we have developed above, PRE-markers have to have a specific shape of their lexical entry, which at its bottom contains both the feature to be spelled 
out (i.e. C1), but also an overlapping feature to which $\mathrm{C} 1$ is added in order to form a left-branch Spec. ${ }^{21}$ This has to be the Q feature, which is the topmost feature of an adjective like intelligent. In addition, more also spells out $\mathrm{C} 2$, and its lexical entry must then be as follows:

$$
[\mathrm{C} 2 \mathrm{P} \mathrm{C} 2[\mathrm{C} 1 \mathrm{P} \mathrm{C} 1 \mathrm{Q}]] \Leftrightarrow / \mathrm{more} /
$$

Including the $\mathrm{Q}$ in the lexical entry is not only theoretically required, but it is also necessary in order to express the suppletion relation between more and much, where much is a $\mathrm{Q}$ marker (rather than a $\mathrm{C} 1$ marker), as argued in De Clercq \& Vanden Wyngaerd (2017). We will say more about suppletion in the next section.

With the lexical entries in place, let us turn to how the derivation proceeds. Suppose we construct QP and spell it out by intelligent. We then go on to merge $\mathrm{C} 1$. However, intelligent cannot spell out $\mathrm{C} 1$, since its lexical entry does not contain it. Therefore, repair operations are triggered. These fail to deliver the right configuration for more, essentially because they fail to construct a constituent with a binary bottom, which is needed for more. The derivation therefore ultimately has to continue by creating a complex Spec in a separate workspace, merging $\mathrm{C} 1$ with

${ }^{21}$ We adopt here the process of complex spec formation as outlined in Starke (2018). De Clercq \& Vanden Wyngaerd (to appear) explore the potential empirical benefits that arise from assuming that no feature overlap is possible between a complex spec and the main derivation. Since this issue is orthogonal to our concerns, we do not explore it any further here. 
Q. Since the Spec spells out directly, the feature C2 is merged with the specifier in the separate workspace. Once the Spec is integrated with the main projection line, the final product looks as follows:

(75)

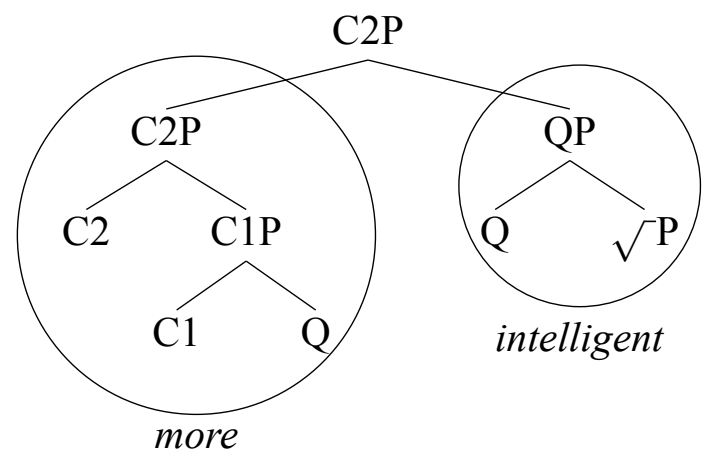

This is (obviously) a different derivation than the one found with Czech QP-sized roots. In Czech, when C1 is added, the derivation is steered in a different direction since the lexicon contains the suffixal $\mathrm{C} 1$ marker $-\check{e} j$ :
a. $[\mathrm{C} 1 \mathrm{P} \mathrm{C} 1] \Leftrightarrow / \check{\mathrm{ej}} /$
b. $[\mathrm{C} 2 \mathrm{P} \mathrm{C} 2] \Leftrightarrow / \check{\mathrm{s}} /$

Due to the existence of - $\check{e} j$, a snowball movement of QP succeeds in producing a remnant $\mathrm{C} 1 \mathrm{P}$ that can be lexicalised (see the $\mathrm{C} 1 \mathrm{P}$ in (77)). This feeds into the next cycle, where $\mathrm{C} 2$ is added, first as a feature to the left of the structure spelled out as root+ěj. But then again, due to 
the lexical entry for $-\check{S}$ in (76b), another snowball movement leads to a successful spellout. The result of the derivation is shown in (77):

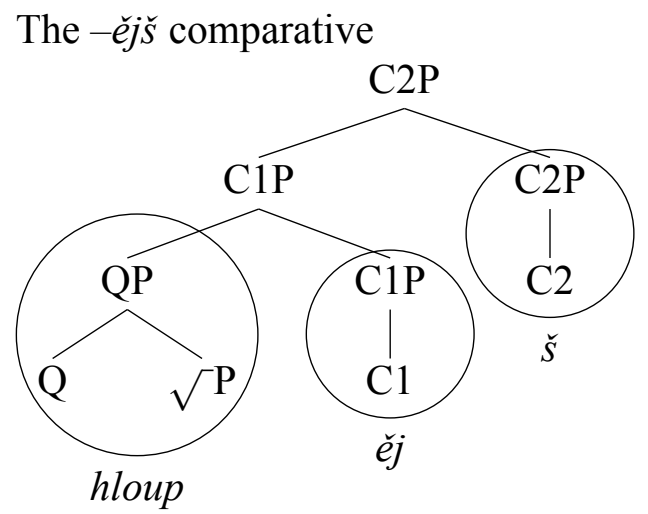

Ultimately, the relevant difference between the different kinds of structures is triggered by the fact that roots and affixes vary in their size and shape. Because of the way spellout proceeds, the roots always spell out as much structure as possible, and the rest is left for post-markers (suffixes) or pre-markers (more). Notice that on this approach, we do not need any ad hoc lexical diacritics to express how a root selects the right allomorph. The correct structures simply arise as the result of an interaction between the spell-out algorithm and the size and shape of the lexical items. 


\section{Suppletion}

\subsection{Portmanteau suppletion and contextual suppletion}

The approach to allomorphy of the comparative in Czech provides us with the possibility to explore a new-more restrictive-approach to suppletion in comparative formation than standardly assumed. In order to show that, we first consider the Distributed Morphology (DM) approach to this phenomenon, in particular the one developed by Bobaljik (2012).

In this approach, there are two different kinds of suppletion, (which we will call) portmanteau suppletion and contextual suppletion. The first kind is instantiated by such pairs as bad-worse. Bobaljik proposes that the suppletive form is a portmanteau for a complex node containing the A node and the CMPR feature. ${ }^{22}$ The Vocabulary Items for this case are shown in (78). They are an intuitive way of encoding that worse in English conveys the meaning of both the root meaning BAD and the meaning of CMPR.
a. $\sqrt{\mathrm{BAD}} \oplus \mathrm{CMPR} \Leftrightarrow$ worse
b. $\sqrt{\mathrm{BAD}} \Leftrightarrow \mathrm{bad}$

22 Bobaljik is noncommittal about the question how this complex node arises, either through fusion of two heads under a new (complex) terminal, or through spellout of a nonterminal node that dominates both heads. 
For pairs such as good-better, Bobaljik proposes that -er spells out the CMPR node, which only leaves the A node for spellout by the root. Hence, there must be a second road to suppletion, which is that of contextual allomorphy, as given by the set of rules in (79).
a. $\sqrt{\mathrm{GOOD}} \Leftrightarrow b e(t t)-/[$ ] CMPR ]
b. $\sqrt{\mathrm{GOOD}} \Leftrightarrow \operatorname{good}$
c. $\mathrm{CMPR} \Leftrightarrow-e r$

These rules say that the form of the root GOOD is bett in the context of CMPR, and good elsewhere. These Vocabulary Items correspond with structures such as (80) and (81), where the circle in (80) indicates that worse is the spellout of two features or heads, and the arrow in (81) indicates that insertion under A is sensitive to the presence of CMPR.
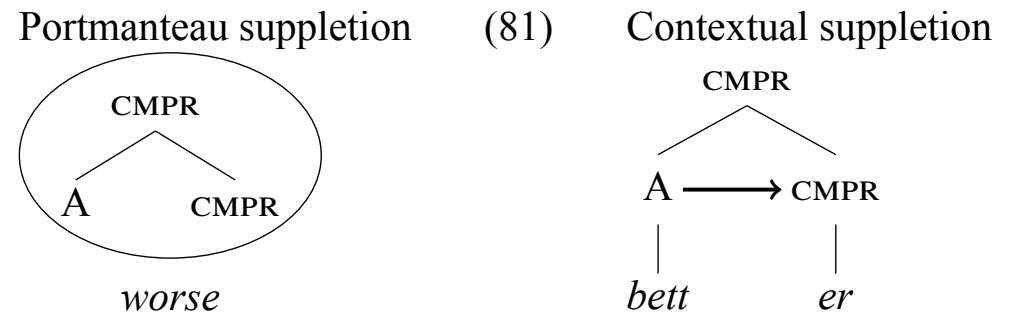

\subsection{Contextual suppletion as portmanteau suppletion}

The strongest argument for maintaining a dual system (where some suppletion is due to portmanteau and some to context sensitivity) is that 
sometimes, suppletion apparently co-occurs with overt marking. For instance, Embick (2016:275) observes that phrasal spellout theories predict that '[s]pecial stem allomorphs of a Root triggered by a feature [X] should not co-occur with an independent realization of [X].' But this prediction is incorrect, as in the case of the comparative bett-er, since suppletion triggered by comparative morphology co-occurs with an overt comparative marker. However, once CMPR is decomposed into $\mathrm{C}_{1}$ and $\mathrm{C}_{2}$, this objection vanishes, and the portmanteau (or phrasal spellout) analysis captures the facts straightforwardly. Specifically, we can say that bett-spells out the root plus $\mathrm{C} 1$, and that $-e r$ spells out $\mathrm{C} 2$. This is shown in (82), where the circles indicate how the syntactic constituents map onto spellouts. This way, bett-differs from the positive good given in (82), and still leaves space for the comparative $-e r$.

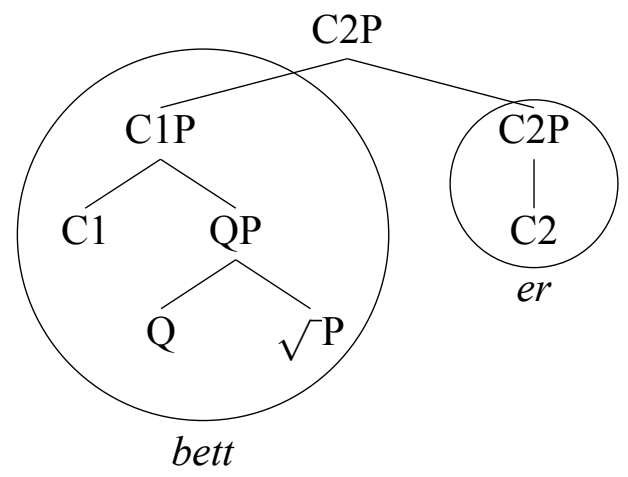




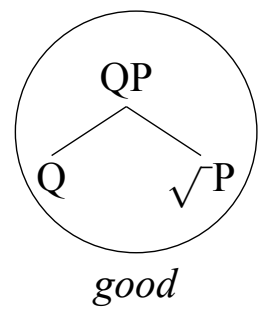

This approach also allows us to capture cases like bad-worse, where there is no apparent double marking, see (84) and (85).

(84)

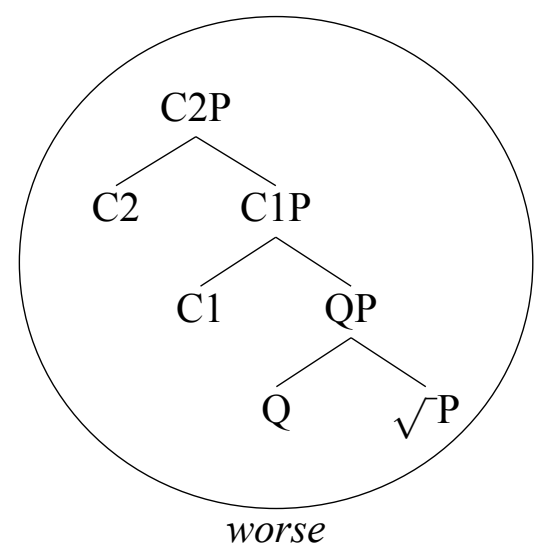

(85)

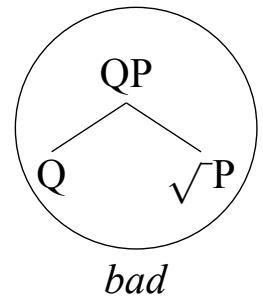

In our theory, suppletive roots have very much the same entries like nonsuppletive roots. For instance, bett-spells out C1P, just like for instance old (recall (63) above). Similarly, a root like worse is similar to a root like ostr- (see recall (26) above). Where suppletive roots differ is that 
they entertain a lexical relation with another lexical item. We represent the lexical relatedness of the good-bett pair by assuming that the lexical item bett- contains a reference (a pointer) to an existing lexical item, good, as in (86a). Similarly, worse contains a pointer to bad.

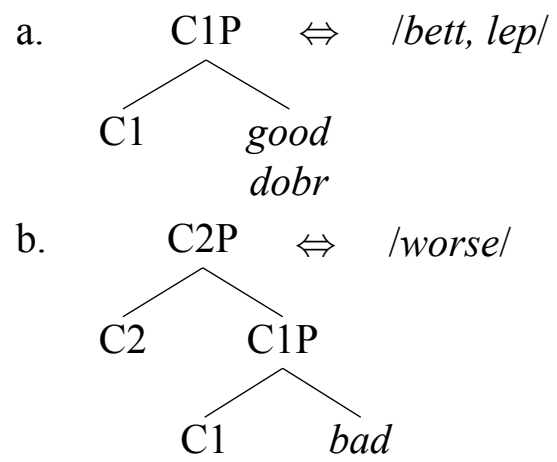

Items with pointers like bett-are read as follows: C1P can be spelled out as bett- only if in the previous cycle QP has been spelled out as good. This means that if the syntax builds QP, only good is a candidate for insertion. Bett- only becomes a candidate after $\mathrm{C} 1$ is merged with good. The insertion of bett- at C1P will prevent the pronunciation of good in the comparative because of Cyclic Override: a successful spellout of C1P will override any earlier spellout of material contained inside C1P.

Non-suppletive roots with a morphological comparative (like old) spell out C1P exactly like bett- in (82), but lack a lexically related counterpart which they point to; as a result, they will be inserted both in the positive degree (as QPs) and as the comparative degree (as C1Ps). 
Note that pointers in our system point to lexical items. This can be interpreted in two ways. First, we can assume that lexical entries can be uniquely identified by their phonological representation. ${ }^{23}$ This might be an issue under the following circumstance: suppose the pointer points to a phonology $/ \alpha /$, and there are two lexical entries with the same phonology $/ \alpha /$, i.e. homophones, but only one of these is suppletive. Under this scenario, phonology is insufficient to uniquely pick out the lexical item that undergoes suppletion. An anonymous reviewer brings up English bad as a relevant case (with reference to Bobaljik's work). This has the usual, negative, meaning, but also a positive one ('awesome, cool'), which has a non-suppletive comparative and superlative (badd-er, badd-est). ${ }^{24}$ The system could deal with this case, minimally, by distinguishing homophones with an index on their phonologies, so that there would be $/ \alpha_{1} /$ and $/ \alpha_{2} /$.

The second potential approach to pointers would be to assume that they point to the full lexical entry, which is a triplet of the type $<$ PHON, SYNT, SEM $>$. Under this approach, the morphologically regular bad 'cool, hip' would count as a different entry from the morphologically irregular $b a d$, since their SEM is different. For practical purposes (to

23 The objection raised in Harley (2014) against identifying roots by their phonologies concerns suppletion, but in our system this objection does not hold because of the existence of the pointer in the suppletive entry.

${ }^{24}$ We assume here, for argument's sake, that the two senses of bad correspond to two different lexical items, but see Arregi \& Nevins (2014) for a different view. 
avoid clumsy notation), lexical items in the postsyntactic lexicon can be assigned a unique (numerical) index, and then pointers can be written using these indices. ${ }^{25}$ Since our system can deal with the problem mentioned in two different ways, i.e. it is compatible with both of the approaches just sketched, we shall not attempt to resolve the issue here.

To round up, at this point, we have rephrased Bobaljik's contextual allomorphy rule in terms of portmanteau suppletion, while at the same time avoiding the problem of apparent double marking. Such a reduction of two mechanisms for suppletion in favour of a single mechanism is theoretically attractive. In addition, it makes our theory also more empirically predictive, as we argue below.

\subsection{The Comparative Suppletion Generalization}

In order to see the prediction which arises when contextual suppletion is abandoned, consider the following reasoning. We start from the fact that under the portmanteau-based approach to suppletion, we get a suppletive root pair only when we have two entries for a root. The positive degree entry spells out a QP, and the suppletive comparative entry adds either $\mathrm{C} 1$ (bett-) or $\mathrm{C} 1$ and $\mathrm{C} 2$ (worse). From this setup, it follows that suppletive roots cannot leave both comparative heads $\mathrm{C} 1$ and $\mathrm{C} 2$ available for insertion. This predicts that a bi-partite comparative marker (which

\footnotetext{
${ }_{25}$ Note that this solution is different from distinguishing roots by an index in the presyn-
} tactic lexicon. 
necessarily spells out both $\mathrm{C} 1$ and $\mathrm{C} 2$ ) is incompatible with suppletion (which spells out minimally $\mathrm{QP}+\mathrm{C} 1$ ). We state the prediction below.

\section{The Comparative Suppletion Generalisation (CSG)}

When the comparative is expressed by two overt markers in addition to the root (or when the comparative marker is a portmanteau that expresses the content of these two markers), there is no suppletion.

The CSG, when applied to English, predicts that syntactic comparatives with more never trigger suppletion: since more spells out both $\mathrm{C} 1$ and $\mathrm{C} 2$, it is predicted to be incompatible with suppletive roots. ${ }^{26}$ This prediction is borne out, and has been observed independently in Bobaljik's study. However, he proposes to subsume it under a different generalisation, namely the Root Suppletion Generalisation (RSG) (Bobaljik 2012:3):

\section{Root Suppletion Generalisation}

Root suppletion is limited to synthetic (i.e. morphological) comparatives.

${ }_{26}$ Empirically, it seems to be the case that prefixes are incompatible with suppletion in general. De Clercq \& Vanden Wyngaerd (to appear) attempt to derive this result within the current framework. See also Moskal (2013) on prefix-suffix asymmetries. 
Bobaljik proposes to derive the RSG as a consequence of a locality restriction, which prevents contextual suppletion between items separated by a word boundary (or, more specifically, by a phrasal projection of the head). What we have seen, however, is that the facts which the RSG derives for English can also be derived by the CSG. In order to see where the predictions of RSG and CSG differ, we would like to turn back to the Czech data, which provide an interesting test case for the two approaches.

\subsection{Suppletion in Czech}

Recall that in Czech, there is a productive bi-morphemic comparative marker $-\check{e} j-\check{s}-(i)$, and two reduced comparative markers $(-\check{S}-(i)$ and the zero marker). The important difference with English is that all the markers, including -ěj-šs, are word-internal, and so the approach based on Bobaljik's RSG and contextual suppletion makes no predictions about this case. In particular, there is no reason to expect that-ěj-š-comparatives should be incompatible with suppletion. However, if we restrict suppletion to portmanteau suppletion (to the exclusion of contextual allomorphy), we expect that there should be no suppletion in- $\check{e} j-\check{s}$-comparatives, because these spell out two different heads, and should therefore block suppletion by the CSG (87). This section explores this prediction and argues that it is in fact borne out. 
Czech descriptive grammars vary as to how many forms are considered suppletive, since the phenomenon is known to be gradual and there is a fuzzy boundary between 'pure' suppletion, irregularity (e.g., irregular lengthening or reduction of the root) and full concatenativity. With this in mind, let us turn to the actual descriptions. Dokulil et al. (1986:379) and Ziková (2016) list five suppletive adjectives which are considered 'fully irregular'; these are given in (89). Osolsobě (2016) considers the first four suppletive, while the last one of them is 'irregular, but not suppletive'.27

\begin{tabular}{|c|c|c|c|c|c|}
\hline & \multicolumn{2}{|c|}{ AdJective } & \multicolumn{2}{|c|}{ ADVERB } & \\
\hline & POS & CMPR & POS & CMPR & \\
\hline a. & dobr-ý & lep-š-í & dobřr-e & lép-e & 'good' \\
\hline & špatn-ý & hor-š-í & špatn-ě & hůřr-e & 'bad' \\
\hline & mal-ý & men-š-í & mál-o & mén-ě & 'small' \\
\hline & velk-ý & vět-š-í & hodn-ě & víc-e & 'big' \\
\hline b. & dlouh-ý & del-š-í & dlouz-e & dél-e & 'long' \\
\hline
\end{tabular}

For completeness, (89) also lists the forms of the corresponding adverbs, in the final two columns. These show the same suppletive root as the adjective (though subject to palatalisation and vowel lengthening), but cru-

27 We consider both of these cases suppletive, as we endorse a theory without morphologically triggered readjustment rules. 
cially lack the $-e \check{j}$, just like their adjectival counterparts. Non-suppletive

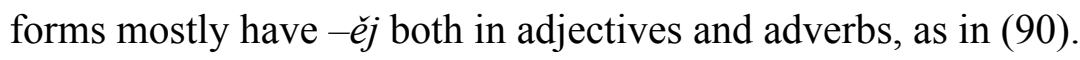

\begin{tabular}{lllll}
\multicolumn{2}{c}{ ADJECTIVE } & \multicolumn{3}{c}{ ADVERB } \\
POS & CMPR & POS & CMPR & \\
\hline rychl-ý & rychl-ej-š-í & rychl-e & rychl-ej-i & 'fast' \\
červen-ý & červen-ěj-š-í & červen-ě & červen-ěj-i & 'red' \\
hloup-ý & hloup-ěj-š-í & hloup-ě & hloup-ěj-i & 'silly' \\
bujar-ý & bujař-ej-š-í & bujař-e & bujař-ej-i & 'merry'
\end{tabular}

As we saw earlier, the implication goes only one way: it is possible for a root to spell out C1P (and hence lack -̌̌j) without being suppletive, i.e. without having a lexically related competitor for the spellout of the positive degree (QP) (see (6) above). Therefore, the theory predicts that some non-suppletive roots may also lack - ěj both in the adjective and the adverb. One case confirming it is given in (91).

\begin{tabular}{lllll}
\multicolumn{2}{c}{ AdjeCtive } & \multicolumn{2}{c}{ AdVERB } \\
POS & CMPR & POS & CMPR & \\
\hline drah-ý & draž-š-í & draz-e & dráž-e & 'expensive'
\end{tabular}

All facts considered, we conclude that all the suppletive adjectives listed in Dokulil et al. (1986:379) and Ziková (2016) belong in the class that 
lacks the $\mathrm{C} 1$ marker $-\check{e} j$. This fact can be seen as nothing but an instance of the CSG, repeated below for convenience:

\section{The Comparative Suppletion Generalisation (CSG)}

When the comparative is expressed by two overt markers in addition to the root (or when the comparative marker is a portmanteau that expresses the content of these two markers), there is no suppletion.

\subsection{Some potential counterexamples}

In this section we take a closer look at two potential counterexamples to the CSG as formulated in (87) above. The most serious challenge to the CSG is posed by the adjective $b r z-k-y$ ' 'early', which has the suppletive comparative $d \check{r}$ ' $v$ - $\check{e} j-s ̌ s-l$ 'former/earlier', with the two comparative suffixes, in apparent contradiction of the CSG. The pair is treated as suppletive in Křivan (2012:26).

However, the overview article Osolsobě (2016) designates the suppletive relation as 'controversial'. The reason for this is that there is a plausible alternative analysis of the comparative $d \check{r} \check{l} v$-ějš- $i$, namely as an adjective derived from the comparative adverb dřiv-e 'earlier'. This analysis is adopted also in Dokulil et al. (1986:382). 
The basic idea of these approaches is that the meaning 'early' is encoded in the Czech grammar primarily through temporal adverbials. This holds both for the positive, where the adverb brz-o 'early' seems to be the basic form, and the adjective $b r z-k-y$ is derived from this adverb by the adjectival $-k$, which we have already discussed above (section 2.4). This is similar to English, where the adjective early (at least historically) also contains an adverb, specifically the adverbial suffix $-l y$ attached on top of a cranberry type of root ere-.

The same derivational relationship carries over (for Czech) to the comparative. The idea is that the comparative adverb is again the base from which the adjective is derived. The derivational relations between adverbs and adjectives are depicted in (92), using simple arrows.

\begin{tabular}{ccccc} 
& POS & & CMPR & 'early' \\
\hline ADV & brz-o & $\Rightarrow$ & dřív-e & \\
& $\downarrow$ & & $\downarrow$ \\
ADJ & brz-k-ý & & dřriv-ější &
\end{tabular}

In addition, the double arrow indicates the suppletive gradation of the adverb. Under this view, there is thus indeed a suppletive relation between the roots $b r z-$ and $d \check{r}^{\prime} v^{-}$, but only in the adverbs. And crucially, here the CSG (87) is obeyed: the form driviv-e indeed lacks the overt C1 marker -ěj, and behaves like all suppletive adverbs, recall (89). No direct derivational relation holds between the two adjectives. 
The only suspicious part of the analysis (92) is the fact that the marker which derives the adjective dř $r$ veějš- $i$ from the adverb is the same as the comparative marker. This gives the impression that the form is actually composed of a suppletive root and the regular bi-morphemic comparative marker on top. However, the -ějš-(i) suffix independently turns adverbs into adjectives, as in the following cases, treated as analogous to the problematic form dřiv-ějš-(i) in Dokulil et al. (1986:382):

\begin{tabular}{|c|c|c|c|}
\hline \multicolumn{2}{|c|}{ AdVERB } & \multicolumn{2}{|c|}{ AdJective } \\
\hline zítr-a & 'tomorrow' & zítřr-ejš-(í) & 'tomorrow's' \\
\hline včer-a & 'yesterday' & včer-ejš-(í) & 'yesterday's' \\
\hline zd-e & 'here' & zd-ejš-(í) & 'local' \\
\hline vn-ě & 'outside' & vn-ějš-(í) & 'outside' \\
\hline vedl-e & 'beside' & vedl-ejš-(í) & 'neighbouring' \\
\hline $\operatorname{tam}$ & 'there' & tam-ějš-(í) & 'the $\mathrm{N}$ there' \\
\hline nyn-í & 'now' & nyn-ějš-(í) & 'present-day' \\
\hline
\end{tabular}

The table shows that there is indeed a suffix ějš-(i), homophonous with the comparative marker, which derives adjectives from temporal and locative adverbs. The resulting forms are incompatible with any regular comparative modifier, like measure phrases, than-phrases, etc. Summing up, we propose that the adjective dřriv-ějšs- $i$ 'earlier' is to be analysed as an adjective derived from a suppletive adverb (for reasons inde- 
pendent of CSG). Once this analysis is adopted, the form is fully consistent with CSG; in fact, the suppletive adverb drív-e adds another piece of evidence in its favour.

The second and final potential counterexample is the adjective 'white' (Janda \& Townsend 2000:25). The comparative is either completely regular, or shows a change of the root vowel. The latter pattern is problematic, since this irregular shape is accompanied by the-ěj-š-(i) marker.

\begin{tabular}{|c|c|c|}
\hline POS & CMPR & SPRL \\
\hline bíl-ý & bíl-ejš-í & nej-bíl-ejš-í \\
\hline bíl-ý & běl-ejš-í & nej-běl-ejš-í \\
\hline
\end{tabular}

The pattern could be captured by saying that bil is an elsewhere form, and that běl-is specifically comparative/superlative. Our theory would then predict that běl is incompatible with -ějšs, contrary to fact. However, there is an independent problem with this analysis, namely that běl also appears in contexts which reject comparative roots. To see this, let us turn to property denoting nouns like stupid-ity. Such nouns are derived in Czech by the suffix -ost '-ness/-ity', which attaches to the positive roots: 


\begin{tabular}{lllll}
\multicolumn{2}{c}{ Adjective } & \multicolumn{2}{c}{ Noun } & \\
POS & CMPR & POS-BASE & CMPR-BASE & \\
\hline špatn-ý & hor-š-í & špatn-ost & *hor-ost & 'bad(ness)' \\
mal-ý & men-š-í & mal-ost & *men-ost & 'small(ness)' \\
nízk-ý & niž-š-í & nízk-ost & *niž-ost & 'low(ness)'
\end{tabular}

With this in mind, it is surprising that the noun for 'whiteness' can be both běl-ost (the preferred choice) and (more marginally) bill-ost. We expect only the latter, as -ost otherwise never attaches to comparative stems. This makes it difficult to analyse běl- as a comparative form.

Another argument to the same effect comes from the phenomenon of A-o-N compounding. This involves a sequence of an adjective and a noun, which normally shows up as a sequence of phrases, as in the first column of (96). This sequence may be subject to adjectivising suffixation with ští. In such circumstances, the adjective of the A-N sequence loses its agreement, and appears followed by an invariant 'connecting morpheme' $-O$ instead. This is shown in the second column of (96).

\begin{tabular}{llll}
\multicolumn{2}{c}{ A+N } & A-o-N compound \\
\hline a. & velk-á & Morav-a & velk-o-morav-ští \\
& great-AGR & Moravia-F & great-o-morav-ian \\
b. & bíl-á & hor-a & běl-o-hor-ští \\
& white-AGR & mountain-F & white-o-mountain-ian
\end{tabular}


What is relevant for us is that in the course of this process, the adjective 'white,' shown in (97b), switches from the root shape bil- to the root shape bèl-. In this context, however, the root shape běl- must be interpreted as a positive degree. The reason is firstly interpretation, and also the fact that suppletive adjectives like velk-y' 'great' show unambiguously positive in the compound. This leads us to suggest that there are actually two independent roots, běl and bill, each specified as a regular positive degree adjective, i.e. QP, and each with its own (almost) full paradigm. This idea, where each of the relevant forms is expected to have two shapes, is depicted below (POS1 is the root that appears in the positive degree, POs2 the one in incorporated adjectives like (96)):

\begin{tabular}{lccccc}
\multicolumn{4}{c}{ Adjective } & Noun & \\
& POS1 & POS2 & CMPR & POs-BASE & \\
\hline ROOT 1 & bílý & bíl- & bílejší & bíl-ost & 'white' \\
ROOT 2 & bělý & běl- & bělejší & běl-ost & 'white'
\end{tabular}

The distribution of the roots in the positive degree is still to be explained, but this cannot be done so by reference to degree, because of the appearance of bèl-in the nominalisation and in the incorporated positive. In sum, we conclude that there are good reasons to assume that the CSG 
holds without exception, and constitutes a strong generalisation that tells us something about how suppletion works. ${ }^{28}$

\section{Faithfulness}

At this point we need to address two different, but related, problems with our assumptions so far. Both of these problems will be solved by introducing a Faithfulness Restriction on the principle of Cyclic Override. To see the issue, recall that we have assumed the existence of adjectives of varying sizes, as in (34) above, repeated here, which are represented arboreally in (98). The two comparative suffixes of Czech are repeated in (35):

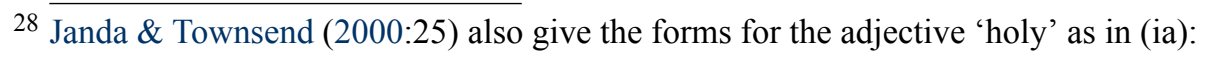

(i)

\begin{tabular}{lllll} 
& POS & CMPR & SPRL & \\
\hline a. & svat-ýy & (??)svět-ější & nej-svět-ější & 'holy' \\
b. & svat-ý & svat-ější & nej-svat-ější & 'holy'
\end{tabular}

These would lead to similar problems as discussed for 'white.' However, according to native-speaker judgements, the comparative is marginal at best, as indicated by the question marks. The superlative is well-formed, but it only has an 'elative' meaning ('holy to a very high degree') and it lacks the relative meaning 'holier than all others'. To express the latter meaning, the 'regular' series would have to be used, as given in (ib). Elative superlatives can be independently shown not to conform to the principles that govern the form of regular comparatives and superlatives. This has been argued by Bobaljik (2012), who shows that elatives display ABA patterns, as in Italian buonomigiore-buonissimo 'good-better-excellent'. Therefore, we set this example aside. 

a.
$\sqrt{ } \quad \Leftrightarrow \quad /$ kluz/
b.
$[\mathrm{QP} Q \sqrt{ }] \Leftrightarrow$ /bujar/
c.
$[\mathrm{C} 1 \mathrm{P} C 1[\mathrm{QP} Q \sqrt{ }]] \Leftrightarrow / \mathrm{star} /$
d. $[\mathrm{C} 2 \mathrm{P} \mathrm{C} 2[\mathrm{C} 1 \mathrm{P} C 1[\mathrm{QP} Q \sqrt{ }]]] \Leftrightarrow /$ ostř $/$
a. $[\mathrm{C} 1 \mathrm{P} \mathrm{C} 1] \Leftrightarrow / \mathrm{ěj} /$
b. $[\mathrm{C} 2 \mathrm{P} \mathrm{C} 2] \Leftrightarrow / \check{\mathrm{s}} /$

(98)

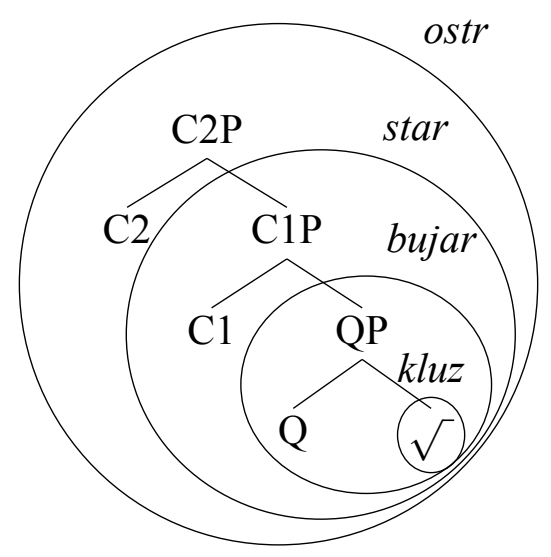

Now suppose that the syntax merges $\sqrt{ }$ and consults the lexicon for spellout, as per the spellout algorithm. ${ }^{29}$ All the lexical items of (34) now qualify for insertion in virtue of the Superset Principle. Two problems arise at this point: the first is how to make a choice between those four types of candidates. Intuitively, what we want is for the choice to

29 To be consistent with our earlier assumptions about the first Merge operation in the derivation, this would require that $\sqrt{ }$ be binary, i.e. composed of at least two even smaller heads. Since the argument we develop is independent of this issue, we ignore this complication for now. 
be free, depending on what one wants to express. But this intuition is incompatible with the Elsewhere Principle, which in the case of multiple candidates for spellout selects the one that is the closest match with the syntactic structure, and discards all others. This would in effect allow only the insertion of adjectives of the kluz-type at $\sqrt{ }$, i.e. the ones with the smallest lexical trees, and rule out insertion of all the other types of adjective. If we go on to merge Q, creating QP, consulting the lexicon finds adjectives of that size and will insert one of them, to the exclusion of all adjectives of different sizes. As a result, a root like star 'old' (lexically specified as C1P) will not be allowed to surface in the positive degree, corresponding to a QP. We shall call this problem the problem of Free Choice: free lexical choice is severely restricted by the system set up so far, in a way that is undesirable.

The free choice problem was noted, in a different but related context, by Marantz $(1995 ; 1996 ; 1997)$. Marantz observes that allowing competition at the level of root insertion will have the effect that a suppletive root will win the competition from all others (since it is more specific), preventing their insertion, and thus Free Choice. Marantz (1997) proposes to solve the problem by claiming that root suppletion does not exist (and that apparent counterexamples like go-went, bad-worse instantiate the functional vocabulary; see also Embick \& Halle 2005). Harley (2014) argues against Marantz' position, claiming instead that 
(syntactic) roots are individuated in the syntax, i.e. prior to vocabulary insertion, by means of a numerical index (following Pfau 2000; 2009; Acquaviva 2009). This implies that the presyntactic lexicon contains a multitude of different $\sqrt{ } \mathrm{s}$, as many as there are vocabulary items. Insertion rules then eliminate the competition between roots by making reference to these indices (except the suppletive ones, which have the same index).

Under this conception, the Free-Choice problem does not arise, as the syntactic computation is free to select a particular $\sqrt{ }$ (say $\sqrt{539}$ ) to start the derivation, and post-syntactic insertion is restricted to the lexical item corresponding to that root. We believe this solution goes against the spirit of modularity, in particular, the separation of the syntax and the (postsyntactic) lexicon. As pointed out in Marantz (1996), the difference between cat and dog is irrelevant to syntax, and therefore syntax should not encode the difference between them. This is an important piece of motivation for late insertion models. Numerical indices on roots reintroduce the difference between cat and $d o g$ in the syntax. Therefore, we do not consider numerical indexes to be a solution the Free-Choice problem. ${ }^{30}$

30 Note also that this solution is unusable if syntax contains functional heads all the way down, as in Ramchand (2008), i.e. if the presyntactic lexicon does not contain a $\sqrt{ }$ at all. See note 7 above. 
The second problem is even more serious, and is in a way the mirror image of the first. We shall call it the problem of Faithfulness. Suppose we found a way to spell out QP as bujar 'merry', and proceeded to merge C1. To derive the correct bujař-ej, spellout driven movement has to apply (as explained in section 3 above). But given (98), there is not just one but two different types of lexical items that could spell out C1P without movement, namely adjectives of size C1P, like star 'old', and adjectives of size C2P, like ostř 'sharp'. Given the fact that the spellout algorithm favours nonmovement over movement derivations, and given the principle of Cyclic Override, at C1P the 'unfaithful' spellouts star 'old' and ostř 'sharp' could override the earlier spellout of bujar 'merry', and the form bujař-ej would never be derivable. We call these spellouts unfaithful because they do not preserve the lexical choice made at the lowest level of insertion. This forced spellout of items which are unfaithful to the original lexical choice results from the following three factors: (i) the spellout algorithm (which favours spellout without movement), (ii) the principle of Cyclic Override (which allows unfaithful spellouts), and (iii) the way we have set up the structure of the lexical items.

The solution to both of our problems (i.e. the Free Choice and the faithfulness problem) lies, we believe, in restricting the applicability of the mechanism of Cyclic Override by imposing a Faithfulness Restriction. A first formulation of the restriction is given in (99)): 
(99) Faithfulness Restriction (FR) (to be modified)

A spellout $/ \alpha /$ may override an earlier spellout $/ \beta /$ iff $/ \alpha /=/ \beta /$

The FR entails that a lexical item may be overridden at a higher level only if the 'overrider' is the same lexical item. In the example we just discussed, bujar 'merry' could never get overridden by star 'old' or ostř 'sharp' at C1P, since they are not the same lexical items. In contrast, if $\sqrt{ } \mathrm{P}$ were spelled out as star, this spellout can (and will) be overridden by star both at QP and C1P, since the overrider is the same lexical item.

As it stands, the FR is overly restrictive, however. If we think back of the way suppletion works, an adjective like good is of size QP and gets overridden by bett at C1P. This is a kind of an override that we want to allow. However, the FR as given in (99) blocks it, since good and bettare not the same lexical item. But there is a sense in which this case is different from the ones where overriding should be blocked. Specifically, there exists a suppletive relationship between good and bett-, which is expressed by the pointer to good in the lexical entry of bett-. Building on this, we can now bring in the suppletive cases by allowing override by lexical items which are either identical, or lexically related by means of a pointer:

\section{(100) Faithfulness Restriction (FR)}

A spellout $/ \alpha /$ may override an earlier spellout $/ \beta /$ iff 

a. $\quad / \alpha /=/ \beta /$
b. the lexical item $/ \alpha /$ contains a pointer to $/ \beta /$

In the case where $/ \alpha /=$ bett and $/ \beta /=\operatorname{good}$, the former will be allowed to override the latter, and so for suppletive spellouts in general. In sum, the FR requires us to be faithful, i.e. to stick to a particular spellout as long as we can, once we have made a Free Choice to insert it at the lowest level of spellout.

Let us now turn to the second problem, namely how to allow for a Free Choice among lexical items. Currently, Free Choice at $\sqrt{ }$ is unavailable because of the Elsewhere Principle (EP), which governs competition between lexical items, and restricts the choice to roots of the kluz class, to the exclusion of adjectives that spell out QP, C1P, or C2P. With the FR in place, we have even limited the options further, since once a lexical entry of the size $\sqrt{ }$ (like $k l u z$ ) has been selected (and the EP would effectively make this the only option), the FR prevents us from overriding this later by any other adjective than the one originally inserted. The solution to this conundrum, we propose, is to give up the EP: at $\sqrt{ }$, Free Choice applies (see also Harley 2014), and the subsequent derivation must be faithful to the original choice. This means that any of the four types of adjectives listed in (34) can be inserted at $\sqrt{ }$. This will steer the derivation in the right direction, with (last resort) move- 
ment derivations for smaller roots (like $k l u z$ ), or nonmovement ones for larger types of roots.

Does the EP have a role to play in the rest of the derivation? We will argue that the answer is no. To see where the EP has traditionally been relevant, consider the competition between lexical items like good and bett. Imagine, for instance, that good was specified as QP, and bett- as C1P, but without a pointer. In such case, good and bett- would both be candidates for the spellout of QP, and we would need the EP to select good and rule out bett-. The EP does that by choosing the candidate which is more specific, i.e. has fewer superfluous features; this prefers good and rules out bett. Can we do without the EP here as well? The answer to this question is already in place. Recall that earlier we suggested an interpretation of pointers which implies that a lexical item with a pointer is only a candidate for spellout if the item pointed to has been spelled out at the lower cycle. This will in fact eliminate bett- from the set of candidates for spellout at QP, since good needs to be spelled out first. Only after $\mathrm{C} 1$ is merged, can bett- be inserted, overriding good.

A second empirical domain where the EP has been used is that of prefixes and suffixes of varying sizes, such as the Case suffixes discussed in Caha (2009). Suppose we have a paradigm as in (101), with three distinct Case endings, indicated by the Greek letters. 
$\begin{array}{ll}\text { (101) NOM } & \mathrm{N}-\alpha \\ \text { ACC } & \mathrm{N}-\beta \\ \text { GEN } & \mathrm{N}-\gamma\end{array}$

In Caha (2009), the lexical items for such endings would look as in (102).
a.
$[\mathrm{K} 1 \mathrm{P} \mathrm{K} 1] \Leftrightarrow / \alpha /$
b.
$[\mathrm{K} 2 \mathrm{P} \mathrm{K} 2[\mathrm{~K} 1 \mathrm{P} \mathrm{K} 1]] \Leftrightarrow / \beta /$
c. $[\mathrm{K} 3 \mathrm{P} \mathrm{K} 3[\mathrm{~K} 2 \mathrm{P} \mathrm{K} 2[\mathrm{~K} 1 \mathrm{P} \mathrm{K} 1]]] \Leftrightarrow / \gamma /$

Now when $\mathrm{K} 1$ is merged, spellout driven movement will raise the noun to the left of the suffix, leaving the structure [K1P K1 ] to be spelled out. At that point, the three lexical items of (102) are all candidates for insertion, since they all contain the syntactic tree. The EP is then needed to ensure that the correct one (the most specific one) is chosen, which would be (102a). By selecting the right candidate, the EP is also important in deriving the *ABA restriction (see Caha 2009 for discussion). So if we want to eliminate the EP altogether, we shall need an alternative take on these cases.

What we propose is to extend the account of suppletion presented above to this case. That is, just as bett-is a suppletive form of good, we claim that the accusative suffix $/ \beta$ / is a suppletive form of the nominative 
$/ \alpha /$ (in the same way, the genitive $/ \gamma /$ suppletes for the accusative $\beta$ ). This means that the lexical entry for the accusative suffix / $\beta$ / contains a pointer to the nominative suffix $/ \alpha /$, as shown in (103a). In the same way, the genitive $/ \gamma /$ contains a pointer to the accusative $/ \beta /$, as shown in (103b):
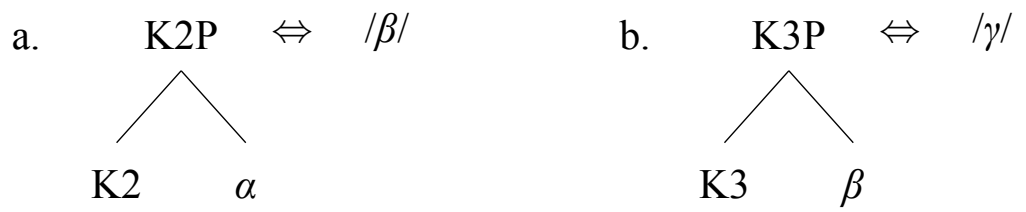

Suppose now the syntax creates [K1P K1]: at this point, only / $\alpha /$ is a candidate for insertion, since $/ \beta /$ is only a candidate if $/ \alpha /$ has been spelled out in the previous cycle (and $/ \gamma /$ only if $/ \beta /$ has been spelled out previously). If subsequently $\mathrm{K} 2$ is merged (and after spec-to-spec raising of the noun to the left of $\mathrm{K} 2$ ), the only candidate is $/ \beta /$, by the same logic, and $/ \beta /$ gets inserted, as required. The spellout $/ \beta /$ overrides the earlier spellout $/ \alpha /$ without violating the FR in virtue of its second clause, which allows suppletive items to override items to which they point in their lexical entries.

In sum, we have put in place a system where the EP is dispensed with. This allows Free Choice for roots at the bottom of the derivation, depending on 'free will', i.e. what one wants to talk about. Further derivations are restricted by the syntactic shape of the root one has cho- 
sen: if it is big, it can grow larger than if it is small. In either case, when the structure available in the root is all 'used up' by the syntactic structure, a number of things can happen as the syntactic tree grows further. The first possibility is that the current spellout is overridden by a suppletive form. The second is that snowball movement applies, and the newly merged feature is spelled out by an additional lexical item (i.e. a suffix). This will now be allowed despite the FR, since snowball movement does not lead to Cyclic Override, but to the agglutination of suffixes. The third possibility is that a new derivation is started in a separate workspace, and merged as a prefix later on. This will also respect the FR in that no Cyclic Override takes place (except internal to the prefix, but this is then subject to the FR).

\section{Conclusion}

In this paper, we proposed an articulated structure of the comparative in terms of two distinct heads, $\mathrm{C} 1$ and $\mathrm{C} 2$. We presented morphological evidence from Czech and Old Church Slavonic in support of these heads, and developed an analysis of root suppletion that makes crucial use of them. In particular, we proposed to reduce all forms of suppletion to portmanteau suppletion, and discussed a generalisation (the Comparative Suppletion Generalisation) which this move gives rise to. Our analysis heavily relied on the idea that adjectival roots come in varying 
sizes. This required us to introduce a Faithfulness Restriction, which takes over most of the work done by the Elsewhere Principle, which can consequently be dispensed with. We were able to achieve all these results relying on the decomposed comparative structure and its interaction with the language particular shapes of lexical entries, which may influence the way derivations unfold via the mechanism of spellout-driven movement.

\section{References}

Acquaviva, P. 2009. Roots and lexicality in distributed morphology. Ms., University College Dublin/Universität Konstanz.

Aitzetmüller, R. 1978. Altbulgarische Grammatik als Einführung in die slavische Sprachwissenschaft, vol. 12 of Monumenta Lingae Slavicae. Freiburg im Bresgau: Weiher.

Aronoff, M. 1976. Word formation in generative grammar. Cambridge, MA: MIT Press.

Arregi, K. \& Nevins, A. 2014. A monoradical approach to some cases of disuppletion. Theoretical Linguistics 40(3/4), 311-330.

BachmannovÁ, J. 2007. Okrajové úseky severovýchodočeské nářeční oblasti z pohledu celočeského (na materiálu korespondenční ankety úJČ). Naše řě 90, 7-19. 
Bethin, C. 1987. Syllable structure and the Polish imperative desinence. Slavic and East European Journal 31, 76-89.

Bobalıiк, J. 2012. Universals In Comparative Morphology. Cambridge, MA: MIT Press.

Bopp, F. 1833. Vergleichende Grammatik des Sanskrit, Zend, Griechischen, Lateinischen, Litthuaischen, Gothischen, und Deutschen. Berlin: Dümmler.

Bopp, F. 1885. A Comparative Grammar of the Sanskrit, Zend, Greek, Latin, Lithuanian, Gothic, German, and Sclavonic Languages. London: Williams and Norgate.

Bresnan, J. 1973. Syntax of the comparative clause construction in English. Linguistic Inquiry 4, 275-343.

CAHA, P. 2009. The Nanosyntax of Case. Ph.D. thesis, University of Tromsø, Tromsø.

CAHA, P. 2017a. Explaining Bobaljik's root suppletion generalization as an instance of the adjacency condition (and beyond). Language use and linguistic structure: Proceedings of the Olomouc Linguistics Colloquium 2016, eds. J. Emonds \& M. Janebová, 193-208. Olomouc: Palacký university.

CAнA, P. 2017b. Suppletion and morpheme order: Are words special? Journal of Linguistics 53(4), 865-896. 
Caha, P. \& Pantcheva, M. to appear. Locatives in Shona and Luganda. Variation and the Split-PP Hypothesis: Comparative approaches to PPs across languages and language domains, eds. J. Garzonio \& S. Rossi. Oxford: Oxford University Press.

Cinque, G. 2005. Deriving Greenberg's universal 20 and its exceptions. Linguistic Inquiry 36(3), 315-332.

Corver, N. 1997. Much-support as a last resort. Linguistic Inquiry 28, $119-164$.

Culpeper, J. \& Leech, G. 1997. The comparison of adjectives in recent British English. To Explain the Present: Studies in the Changing English Language in Honour of Matti Rissanen, eds. T. Nevalainen \& L. Kahlas-Tarkka, 353-373. Mémoires de la Société Néophilologique de Helsinki.

De ClercQ, K. 2013. A Unified Syntax of Negation. Ph.D. thesis, Ghent University, Gent.

De ClercQ, K. 2017. The internal syntax of Q-words. Linguistics in the Netherlands 34, 31-46.

De ClercQ, K. \& Vanden Wyngaerd, G. 2017. *ABA revisited: evidence from Czech and Latin degree morphology. Glossa 2(1), 69: $1-32$.

De Clerce, K. \& Vanden Wyngaerd, G. to appear. Unmerging analytic comparatives. Jezikoslovlje . 
Dokulil, M., Horálek, K., Hưrková, J., Knappová, M. \& Petr, J. 1986. Mluvnice češtiny 1. Fonetika. Fonologie. Morfologie a morfemika. Tvoření slov. Praha: Academia.

Eмвіск, D. 2016. On the targets of phonological realization. The Morphosyntax-Phonology Connection: Locality and Directionality at the Interface, eds. V. Gribanova \& S.S. Shih, 255-283. Oxford: Oxford University Press.

Embick, D. \& Halle, M. 2005. On the status of stems in morphological theory. Romance Languages and Linguistic Theory 2003, eds. T. Geerts, I. van Ginneken \& H. Jacobs, 59-88. Amsterdam: John Benjamins.

EnZINNA, N. 2017. How speakers select synthetic and analytic forms of English comparatives: An experimental study. Proceedings of the Linguistic Society of America 2, 46:1-15.

FÁBregas, A. 2007. An exhaustive lexicalisation account of directional complements. Nordlyd, special issue on Space, Motion, and Result, eds. M. Bašić, M. Pantcheva, M. Son \& P. Svenonius, 165-199. No. 34.2 in Tromsø Working Papers on Language and Linguistics, Tromsø: CASTL, University of Tromsø.

Gouskova, M. \& Ahn, S. 2016. Sublexical phonotactics and English comparatives. Ms. NYU. 
Graziano-King, J. 1999. Acquisition of comparative forms in English. Ph.D. thesis, CUNY, New York.

Graziano-King, J. \& Smith Cairns, H. 2005. Acquisition of English comparative adjectives. Journal of Child Language 32(2), 345-373.

Harley, H. 2014. On the identity of roots. Theoretical Linguistics 40, $225-276$.

Haugen, J.D. \& Siddiqi, D. 2016. Towards a restricted realization theory: Multimorphemic monolistemicity, portmanteaux, and postlinearization spanning. Morphological metatheory, eds. D. Siddiqi \& H. Harley, 343-385. Amsterdam: John Benjamins.

HilPERT, M. 2008. The English comparative-language structure and language use. English Language and Linguistics 12, 395-417.

JAnda, L. \& Townsend, C. 2000. Czech, vol. 125 of Languages of the World/Materials. Munich: Lincom Europa.

Jespersen, O. 1954. A Modern English Grammar on Historical Principles. London: George Allen \& Unwin.

Karlík, P., Nekula, M. \& Rusínová, Z. 1995. Příruční mluvnice češtiny. Praha: Nakladatelství Lidové noviny.

KoseK, P. 2014. Historická mluvnice češtiny I. Brno: Masarykova univerzita.

KŘIVAN, J. 2012. Komparativ v korpusu: explanace morfematické struktury českého stupňování na základě frekvence tvarů. Slovo a sloves- 
nost $73,13-45$.

LAFAVE, N. 2005. The most apt experimental investigation of English comparative and superlative formation. University of Pennsylvania Working Papers in Linguistics 21, 1-10.

Lamprecht, A., Šlosar, D. \& Bauer, J. 1986. Historická mluvnice češtiny. Prague: Stàtní pedagogickè nakladatelství.

Lunt, H. 2001. Old Church Slavonic Grammar. Berlin: Mouton de Gruyter.

Marantz, A. 1995. A late note on late insertion. Explorations in generative grammar: A festschrift for Dong-Whee Yang, eds. Y.S. Kim, B.C. Lee, K.J. Lee, K.K. Yang \& J.K. Yoon, 396-413. Seoul: Hankuk.

Marantz, A. 1996. Cat as a phrasal idiom: consequences of late insertion in Distributed Morphology. Ms., MIT.

Marantz, A. 1997. No escape from syntax: Don't try morphological analysis in the privacy of your own lexicon. University of Pennsylvania Working Papers in Linguistics, vol. 4, eds. A. Dimitriadis, L. Siegel, C. Surek-Clark \& A. Williams, 201-225. University of Pennsylvania.

Matushansky, O. 2013. More or better: On the derivation of synthetic comparatives and superlatives in English. Distributed Morphology Today: Morphemes for Morris Halle, eds. O. Matushansky 
\& A. Marantz, 59-78. Cambridge, MA: MIT Press.

Mondorf, B. 2003. Support for more-support. Determinants of Grammatical Variation in English, eds. G. Rohdenburg \& B. Mondorf, 251-304. Berlin: Mouton de Gruyter.

Mondorf, B. 2009. More Support for More-support. The Role of Processing Constraints on the Choice between Synthetic and Analytic Comparative Forms. Amsterdam: John Benjamins.

Moskal, B. 2013. A Case Study in Nominal Suppletion. Ph.D. thesis, University of Connecticut, Storrs, CT.

OsolsobĚ, K. 2016. Komparativ. Nový encyklopedický slovník češtiny, eds. P. Karlík, M. Nekula \& J. Pleskalová, 839. Praha: Nakladatelství Lidové noviny.

Pfau, R. 2000. Features and categories in language production. Ph.D. thesis, Johann Wolfgang Goethe-Universität, Frankfurt am Main.

Pfau, R. 2009. Grammar as processor: a distributed morphology account of spontaneous speech errors. Amsterdam: Benjamins.

Quirk, R., Greenbaum, S., Leech, G. \& Svartvik, J. 1985. A Comprehensive Grammar of the English Language. London: Longman.

Radkevich, N. 2010. On Location: The structure of case and adpositions. Ph.D. thesis, University of Connecticut, Storrs, CT.

Ramchand, G. 2008. Verb Meaning and the Lexicon. Cambridge, Massachusetts: MIT Press. 
Rubach, J. 1986. Abstract vowels in three dimensional phonology: The yers. The Linguistic Review 5, 247-280.

ScheER, T. 2001. Čeština ve Varšavě. Handout of a course at Instytut Anglistiki Uniwersytet Warszawski, http://www.unice.fr/scheer/wa/ceskyHdt.pdf.

SiddiQI, D. 2006. Minimize Exponence: Economy Effects on the Morphosyntactic Component of the Grammar. Ph.D. thesis, University of Arizona.

Starke, M. 2004. On the inexistence of specifiers and the nature of heads. Structures and Beyond, vol. 3 of The Cartography of Syntactic Structures, ed. A. Belletti, 252-268. Oxford: Oxford University Press.

StArke, M. 2009. Nanosyntax: A short primer to a new approach to language. Nordlyd 36, 1-6.

Starke, M. 2018. Complex left branches, spellout, and prefixes. Exploring Nanosyntax, eds. L. Baunaz, K. De Clercq, L. Haegeman \& E. Lander, 239-249. Oxford: Oxford University Press.

SzPYRA, J. 1992. Ghost segments in nonlinear phonology: Polish yers. Language 68, 277-312.

Taraldsen, K.T., Medová, L.T. \& Langa, D. 2018. Class prefixes as specifiers in Southern Bantu. Natural Language and Linguistic Theory 1-56. 
Williams, E. 2003. Representation Theory. Cambridge, Massachusetts: MIT Press.

Zıкová, M. 2016. Supletivismus. Nový encyklopedický slovník češtiny, eds. P. Karlík, M. Nekula \& J. Pleskalová, 1795-1796. Praha: Nakladatelství Lidové noviny. 
Pavel Caha

Masarykova Univerzita

Arna Nováka 1

60200 Brno

Czech Republic

pavel.caha@phil.muni.cz

Karen De Clercq

FWO/Ghent University

Blandijnberg 2

9000 Gent

Belgium

karen.declercq@ugent.be

Guido Vanden Wyngaerd

KU Leuven

Warmoesberg 26

1000 Brussel

Belgium

guido.vandenwyngaerd@kuleuven.be 